\title{
Guidelines for antiretroviral therapy in adults
}

\author{
by the Southern African HIV Clinicians Society
}

Graeme Meintjes, Gary Maartens (Chairpersons of the Adult Guidelines Committee), Andrew Boulle, Francesca Conradie, Eric Goemaere, Eric Hefer, Dave Johnson, Moeketsi Mathe, Yunus Moosa, Regina Osih, Theresa Rossouw, Gilles van Cutsem, Ebrahim Variava, Francois Venter (Expert Panel Members), Dave Spencer (Reviewer), on behalf of the Southern African HIV Clinicians Society

Corresponding author: G Meintjes (graemein@mweb.co.za)

Disclaimer: Specific recommendations provided here are intended only as a guide to clinical therapy, based on expert consensus and best current evidence. Treatment decisions for patients should be made by their responsible clinicians, with due consideration for individual circumstances. The most current version of this document should always be consulted.

These guidelines are intended as an update to those published in the Southern African Journal of HIV Medicine in January 2008. Since the release of the previous guidelines, the scaleup of antiretroviral therapy (ART) in Southern Africa has continued to grow. Cohort studies from the region show excellent clinical outcomes; however, ART is still being started late (in advanced disease), resulting in relatively high early mortality rates. New data on antiretroviral (ARV) tolerability in the region and several new ARV drugs have become available. Although currently few in number, some patients in the region are failing protease inhibitor (PI)based second-line regimens. To address this, guidelines on third-line (or 'salvage') therapy have been expanded.

S Afr J HIV Med 2012;13(3):114-133. DOI:10.7196/SAJHIVMED.862

\section{Underlying principles}

While many ART guidelines are available internationally, these guidelines have been written to address issues relevant to Southern Africa. The following general principles underpinned the writing process:

- South Africa is a middle-income country whereas certain other countries in the region are low-income countries; therefore, affordability was taken into account.

- Only treatment and diagnostic options available in Southern Africa were included.

- We recognised the need to bridge the gap in treatment recommendations between public and private sector programmes, considering that many patients transition between the 2 sectors for treatment.

- The guidelines are intended to reflect 'best practice' while it is acknowledged that certain recommendations are aspirational for poorly resourced settings, the unavailability of diagnostic/monitoring tests should not be a barrier to providing ART to those in need.

- There has been a shift to view treatment as a means of HIV prevention. The evidence base for this exists for serodiscordant couples; recommendations in this regard are included in these guidelines and additional data from community studies are awaited.

- References for key new recommendations were included to address the need for supporting evidence.

\section{Goals of therapy}

The primary goals of ART are to:

- improve quality of life

- reduce HIV-related morbidity and mortality

- provide maximal and durable suppression of viral load

- restore and/or preserve immune function.

These goals are achieved by completely suppressing viral replication for as long as possible using well-tolerated and sustainable treatment. With prolonged viral suppression, the CD4 lymphocyte count usually increases, which is accompanied by partial restoration of pathogen-specific immune function. For most patients, this results in a dramatic reduction in the risk of HIV-associated morbidity and mortality. It is still unclear whether immune function ever returns to full normality. Longterm cohorts will provide answers, but for now, and for practical purposes, clinicians should treat patients who adhere to ART with the anticipation of a near-normal life expectancy.

\section{Standard of care}

Maximally suppressive ART regimens should be used to obtain the best results and to prevent resistance. In the region, nonsuppressive regimens such as mono/dual nucleoside reverse transcriptase inhibitor (NRTI) therapies have historically been used. The initiation of such therapies is now strongly discouraged. However, non-suppressive regimens have a role in the prevention of mother-to-child transmission (PMTCT) and in post-exposure prophylaxis (PEP) for healthcare workers following occupational exposure. Furthermore, they are probably effective following sexual exposure. For further guidance:

Southern African HIV Clinicians Society. Post-exposure prophylaxis.

Southern African Journal of HIV Medicine 2008;9:36-45. 


\section{Classes of ARV agents and their mechanisms of action}

The most commonly used ARV agents in the region inhibit 1 of 3 key HIV enzymes that are required by the virus for intracellular replication (Table 1):

- reverse transcriptase - essential for completion of the early stages of HIV replication

- protease - required for the assembly and maturation of fullyinfectious viral progeny

- integrase - required for the integration of proviral DNA into the host chromosomal DNA.

\section{ARV agents currently available in Southern Africa (Table 2)}

\subsection{Notes}

Different fixed-dose drug combinations are increasingly being made available. The oldest combination is zidovudine (AZT)/lamivudine (3TC), but a number of other 2 - 3 fixed-dose combinations are now available in Southern Africa. These reduce the burden of multiple pills and improve adherence. However, side-effects remain as described in Table 2.

Low-dose ritonavir is used to 'boost' the concentration of other PIs. It is always used with lopinavir (LPV) (fixed-dose combination) and saquinavir (SQV) and is strongly encouraged with other PIs. The following PIs are recommended for use: LPV/ritonavir (LPV/r), atazanavir/ritonavir (ATV/r) and darunavir/ritonavir (DRV/r). Patients receiving older PIs (e.g. SQV and indinavir) should be switched to these (consult an expert if the patient's viral load is not suppressed). We recommend against regimens containing dual ritonavir-boosted PIs, as there is no evidence for superior efficacy ${ }^{1}$ and significant side-effects are likely.
Combinations to be avoided include: (i) AZT plus d4T (antagonism); (ii) tenofovir (TDF) plus didanosine (ddI) (associated with poorer virological and immunological responses and increased toxicity); and (iii) D4T plus ddI (associated with a very high risk for mitochondrial toxicities such as lactic acidosis and peripheral neuropathy).

\section{Indications for starting ART}

Indications for ART initiation are summarised in Table 3. ART initiation is never an emergency, unless used for PEP or PMTCT. However, patients with profound immunosuppression are at significant risk of opportunistic illnesses, and should be assessed rapidly and initiated on ART as soon as adherence is assured. The following investigations are recommended prior to initiating ART:

- alanine transaminase (ALT)

- full blood count (FBC)

- serum creatinine and calculate creatinine clearance: avoid TDF if creatinine clearance is $<50 \mathrm{ml} / \mathrm{min}$; other NRTIs, except abacavir $(\mathrm{ABC})$, require dose adjustment if creatinine clearance is $<50 \mathrm{ml} / \mathrm{min}$ (see the modified Cockgraft-Gault equation - Table 9)

- urinalysis for proteinuria

- hepatitis B surface antigen

- CD4 count.

Where feasible, a serum or plasma cryptococcal antigen test should be performed in patients starting ART with a CD4 count $<100$ cells/ $\mu \mathrm{l}$, to screen for early cryptococcal disease and to initiate pre-emptive treatment if needed. In addition, a baseline HIV viral load should be performed where feasible.

ART should be deferred until patients are prepared to commit to long-term treatment and maintaining good treatment adherence. However, efforts should be made to avoid lengthy indecision that may result in avoidable clinical deterioration and death.

Table 1. Classes of ARV agents

\begin{tabular}{|c|c|c|c|}
\hline Class & Abbreviation & Mechanism of action & Specific action \\
\hline $\begin{array}{l}\text { Nucleoside and nucleotide reverse } \\
\text { transcriptase inhibitors }\end{array}$ & NRTIs and NtRTIs & $\begin{array}{l}\text { Reverse } \\
\text { transcriptase } \\
\text { inhibition }\end{array}$ & $\begin{array}{l}\text { Nucleic acid analogues that mimic } \\
\text { the normal building blocks of DNA, } \\
\text { preventing transcription of viral RNA to } \\
\text { DNA }\end{array}$ \\
\hline $\begin{array}{l}\text { Non-nucleoside reverse } \\
\text { transcriptase inhibitors }\end{array}$ & NNRTIs & $\begin{array}{l}\text { Reverse } \\
\text { transcriptase } \\
\text { inhibition }\end{array}$ & $\begin{array}{l}\text { Small compounds shaped to fit into the } \\
\text { genomic HIV binding site of reverse } \\
\text { transcriptase and directly inhibit its action }\end{array}$ \\
\hline Protease inhibitors & PIs & $\begin{array}{l}\text { Protease } \\
\text { inhibition }\end{array}$ & $\begin{array}{l}\text { Inhibit the final maturation stages of HIV } \\
\text { replication, resulting in the formation of } \\
\text { non-infective viral particles }\end{array}$ \\
\hline Entry inhibitors* & - & Entry inhibition & $\begin{array}{l}\text { Bind to viral gp41 or host cell CD4 or } \\
\text { chemokine (CCR5) receptors }\end{array}$ \\
\hline $\begin{array}{l}\text { Integrase inhibitors } \\
\text { (also termed integrase strand } \\
\text { transfer inhibitors) }\end{array}$ & InSTIs & Inhibit viral integration & $\begin{array}{l}\text { Prevent the transfer of proviral DNA } \\
\text { strands into the host chromosomal DNA }\end{array}$ \\
\hline
\end{tabular}


Table 2. Dose and common adverse drug reactions of ARV agents available in Southern Africa

\begin{tabular}{|c|c|c|c|}
\hline Generic name & $\begin{array}{l}\text { Class of } \\
\text { drug }^{*}\end{array}$ & Recommended dosage & Common or severe adverse drug reactions ${ }^{\dagger}$ \\
\hline Zidovudine (AZT) & NRTI & 300 mg 12-hourly & $\begin{array}{l}\text { Bone marrow suppression, gastro-intestinal (GI) upset, } \\
\text { headache, myopathy, hyperlactataemia/steatohepatitis } \\
\text { (medium potential), lipo-atrophy }\end{array}$ \\
\hline Didanosine (ddI) & NRTI & $\begin{array}{l}400 \mathrm{mg} \text { daily }(250 \mathrm{mg} \text { daily if }<60 \mathrm{~kg} \text { ) } \\
\text { taken on an empty stomach } \\
\text { (enteric coated formulation preferred) }\end{array}$ & $\begin{array}{l}\text { Peripheral neuropathy, pancreatitis, nausea, diarrhoea, } \\
\text { hyperlactataemia/steatohepatitis (high potential) }\end{array}$ \\
\hline Lamivudine (3TC) & NRTI & $150 \mathrm{mg}$ 12-hourly or $300 \mathrm{mg}$ daily & $\begin{array}{l}\text { Anaemia (pure red cell aplasia) (rare), hyperlactataemia/ } \\
\text { steatohepatitis (very low potential) }\end{array}$ \\
\hline Stavudine (D4T) & NRTI & $\begin{array}{l}30 \mathrm{mg} 12 \text {-hourly } \\
\text { Note: higher doses for }>60 \mathrm{~kg} \text { no } \\
\text { longer recommended due to toxicity }\end{array}$ & $\begin{array}{l}\text { Peripheral neuropathy, lipo-atrophy, hyperlactataemia/ } \\
\text { steatohepatitis (high potential), pancreatitis, HIV- } \\
\text { associated neuromuscular weakness syndrome (HANWS) } \\
\text { (rare), dyslipidaemia }\end{array}$ \\
\hline Abacavir (ABC) & NRTI & $300 \mathrm{mg}$ 12-hourly or $600 \mathrm{mg}$ daily & $\begin{array}{l}\text { Hypersensitivity reaction, hyperlactataemia/ } \\
\text { steatohepatitis (very low potential) }\end{array}$ \\
\hline Tenofovir (TDF) & NtRTI & $300 \mathrm{mg}$ daily & $\begin{array}{l}\text { Renal failure, tubular wasting syndrome, reduced bone } \\
\text { mineral density, hyperlactataemia/steatohepatitis (very low } \\
\text { potential) }\end{array}$ \\
\hline Emtricitabine (FTC) & NRTI & $200 \mathrm{mg}$ daily & $\begin{array}{l}\text { Palmar hyperpigmentation, hyperlactataemia/ } \\
\text { steatohepatitis (very low potential) }\end{array}$ \\
\hline Nevirapine (NVP) & NNRTI & $\begin{array}{l}200 \mathrm{mg} \text { daily for } 14 \text { days then } 200 \mathrm{mg} \\
\text { 12-hourly }\end{array}$ & Rash, hepatitis \\
\hline Efavirenz (EFV) & NNRTI & $600 \mathrm{mg}$ at night & $\begin{array}{l}\text { Central nervous system symptoms (vivid dreams, problems } \\
\text { with concentration, confusion, mood disturbance, } \\
\text { psychosis), rash, hepatitis, gynaecomastia }\end{array}$ \\
\hline Etravirine (ETV) & NNRTI & 200 mg 12-hourly & Rash, hepatitis \\
\hline $\begin{array}{l}\text { Indinavir (IDV) } \\
\text { (rarely used) }\end{array}$ & PI & $\begin{array}{l}800 \mathrm{mg} 12 \text {-hourly with } 100 \mathrm{mg} \\
\text { ritonavir } 12 \text {-hourly } \\
\text { No food restrictions } \\
\text { Maintain high fluid intake }\end{array}$ & $\begin{array}{l}\text { Kidney stones, unconjugated hyperbilirubinaemia (visible } \\
\text { jaundice in minority of patients), GI disturbances, hair loss, } \\
\text { hyperglycaemia, headache, dyslipidaemia }\end{array}$ \\
\hline Atazanavir (ATV) & PI & $\begin{array}{l}400 \mathrm{mg} \text { daily (only if ART-naive) or } \\
300 \mathrm{mg} \text { with ritonavir } 100 \mathrm{mg} \text { daily } \\
\text { (preferable) } \\
\text { With TDF } 300 / 100 \mathrm{mg} \text { daily and with } \\
\text { EFV } 400 / 100 \mathrm{mg} \text { daily }\end{array}$ & $\begin{array}{l}\text { Unconjugated hyperbilirubinaemia (visible jaundice in } \\
\text { minority of patients), dyslipidaemia (low potential), renal } \\
\text { stones (rare), hepatitis }\end{array}$ \\
\hline $\begin{array}{l}\text { Lopinavir/ritonavir } \\
\text { (LPV/r) }\end{array}$ & Boosted PI & $\begin{array}{l}400 / 100 \mathrm{mg} 12 \text {-hourly or } 800 / 200 \mathrm{mg} \\
\text { daily (only if PI-naive). }\end{array}$ & GI upset, dyslipidaemia, hepatitis \\
\hline Darunavir (DRV) & PI & $\begin{array}{l}600 \mathrm{mg} \text { 12-hourly with } 100 \mathrm{mg} \\
\text { ritonavir } 12 \text {-hourly or } 800 / 100 \mathrm{mg} \\
\text { daily (only if PI-naive) }\end{array}$ & $\begin{array}{l}\text { GI upset, rash, dyslipidaemia, hepatitis } \\
\text { Contains sulphonamide moiety (use with caution in } \\
\text { patients with sulpha allergy) }\end{array}$ \\
\hline $\begin{array}{l}\text { Saquinavir } \\
\text { (SQV) (hard gel } \\
\text { formulation, rarely } \\
\text { used) }\end{array}$ & PI & $\begin{array}{l}1000 \mathrm{mg} \text { with } 100 \mathrm{mg} \text { ritonavir } \\
12 \text {-hourly, or } 1600 \mathrm{mg} \text { with } 100 \mathrm{mg} \\
\text { ritonavir daily (only if PI-naive) } \\
\text { Take with a fatty meal, or up to } 2 \\
\text { hours after meal }\end{array}$ & $\begin{array}{l}\text { GI disturbance (mild), hepatitis, hyperglycaemia, } \\
\text { dyslipidaemia }\end{array}$ \\
\hline Raltegravir (RAL) & InSTI & 400 mg 12-hourly & Rash (rare), headache, GI upset \\
\hline \multicolumn{4}{|c|}{$\begin{array}{l}\text { *All protease inhibitors (PIs) may be associated with cardiac conduction abnormalities (especially PR prolongation). This seldom results in clinically significant effects, but caution } \\
\text { should be taken when co-prescribing other drugs that cause delayed cardiac conduction, such as macrolides. }\end{array}$} \\
\hline \multicolumn{4}{|c|}{${ }^{\dagger}$ Life-threatening reactions are indicated in bold. } \\
\hline
\end{tabular}




\subsection{Rationale for these guidelines 6.1.1 CD4 threshold}

A randomised trial in Haiti demonstrated reduced mortality and incident tuberculosis (TB) in patients starting ART at a CD4 threshold $<350$ cells/ $\mu$ l (compared with patients waiting to start therapy at $<200$ cells $/ \mu \mathrm{l}){ }^{2}$ Some observational data suggest that reduced morbidity and mortality are associated with starting ART even earlier (at CD4 thresholds of 500 cells/ $\mu$ l or above that). ${ }^{3-6}$ However, these data are derived from retrospective studies with methodological issues and probable residual confounding. If there is benefit to patients starting ART at CD4 counts $>350$ cells/ $\mu$ l, the benefit is likely to be small, since HIV-related events at high CD4 counts are rare. A randomised controlled trial (RCT) (HPTN052) showed reduced morbidity but not mortality associated with starting ART at a CD4 count of $350-550$ cells/ $\mu \mathrm{l}$ (compared with $<250$ cells $/ \mu \mathrm{l}){ }^{7}$ However, again, the absolute benefits were small. Definitive evidence regarding earlier ART initiation is awaited from an ongoing RCT, the START study (http://clinicaltrials. gov/ct2/show/NCT00867048).

\subsubsection{Treating WHO stage 3}

Many observational studies have shown that TB (the most common World Health Organization (WHO) stage 3 condition associated with HIV) accelerates HIV disease progression and increases mortality. ${ }^{8}$ We advise that an episode of HIV-associated TB (i.e. TB diagnosed at the time of seropositive HIV test) is a sufficient criterion for ART, but not remote episodes of TB when the patient's HIV status was unknown.

\subsubsection{Serodiscordant couples}

The HPTN052 trial showed that treating the HIV-infected partner in a serodiscordant relationship with ART was associated with a $96 \%$ reduction in transmission risk to the uninfected partner. ${ }^{7}$

\subsection{Starting ART in patients with TB}

Decisions regarding the timing of ART in patients with TB should be made on the basis of the $\mathrm{CD} 4$ count:

- CD4 count $\leq \mathbf{5 0}$ cells/ $\boldsymbol{\mu l}$ : ART should be regarded as urgent, and the aim should be to start therapy after 2 weeks of TB treatment. Three RCTs ${ }^{9-11}$ have demonstrated that this approach reduces AIDS progression and mortality. It is advised to commence ART after it is clear that the patient's TB symptoms are improving and that TB therapy is tolerated.

- CD4 count $>\mathbf{5 0}$ cells/ $\mu$ l: ART should be delayed until after the intensive phase of TB treatment (2 months) unless the patient has other serious HIV-related conditions (e.g. Kaposi's sarcoma or HIV encephalopathy). The longer delay before commencing ART in this group is expected to reduce the risk of shared toxicity (as the patient will then be receiving fewer TB drugs) and to reduce the risk of the immune reconstitution inflammatory syndrome (IRIS) (section 15). The RCTs did not show a higher risk of AIDS progression/mortality in this group when ART initiation was delayed until 2 months after starting TB treatment. ${ }^{9-11}$

- There are important drug interactions and shared side-effects when ART is co-administered with TB therapy (section 13.1).

\section{Table 3. Indications for ART*}

\begin{tabular}{|c|c|}
\hline \multicolumn{2}{|l|}{ Clinical diagnoses (irrespective of CD4 count) } \\
\hline WHO clinical stage 3 and $4^{\dagger}$ & ART recommended \\
\hline $\begin{array}{l}\text { Other severe HIV-related disorders, e.g.: }{ }^{\ddagger} \\
\text { Immune thrombocytopenia } \\
\text { Thrombotic thrombocytopenic purpura } \\
\text { Polymyositis } \\
\text { Lymphocytic interstitial pneumonitis }\end{array}$ & ART recommended \\
\hline $\begin{array}{l}\text { Non HIV-related disorders: }{ }^{5} \\
\text { Malignancies (excluding localised malignancies) } \\
\text { Hepatitis B } \\
\text { Hepatitis C }\end{array}$ & ART recommended \\
\hline Any condition requiring long-term immunosuppressive therapy & ART recommended \\
\hline \multicolumn{2}{|l|}{ CD4 counts } \\
\hline$<350$ cells $/ \mu \mathrm{l}$ & ART recommended \\
\hline$>350$ cells $/ \mu \mathrm{l}$ & Defer ART \\
\hline \multicolumn{2}{|l|}{ HIV-infected partner in serodiscordant relationship } \\
\hline Regardless of CD4 count or clinical diagnoses & $\begin{array}{l}\text { Offer ART and discuss safe sex (discussion must involve both } \\
\text { partners) }\end{array}$ \\
\hline \multicolumn{2}{|l|}{ 'Note that EITHER listed clinical diagnoses OR CD4 strata would be an indication for ART. } \\
\hline \multicolumn{2}{|c|}{ 'Specialist input required. Note that this list is not exhaustive - any other severe HIV-related disorder should be considered an indication for ART. } \\
\hline $\begin{array}{l}\text { Specialist input required. Other disorders that may benefit from improvement in immune fut } \\
\text { risk factor for vascular disease, patients with symptomatic vascular disease or diabetes mellit }\end{array}$ & $\begin{array}{l}\text { be considered as an indication to start ART. Also, given that untreated HIV appears to be a } \\
\text { d for earlier ART. }\end{array}$ \\
\hline
\end{tabular}


- When ART is commenced, patients should be warned that TB symptoms or signs may temporarily worsen and new features may occur in the first 3 months as a result of TB-IRIS.

- Unless contra-indicated, cotrimoxazole prophylaxis should be initiated in patients with HIV-associated TB.

- Patients with TB meningitis (TBM) starting ART immediately or at 2 months following diagnosis were shown to have similar high mortality, with more complications in the former. ${ }^{12}$ We recommend starting ART 2 - 8 weeks after TBM diagnosis.

\subsection{Starting ART in patients with other opportunistic diseases/infections}

For patients with cryptococcal meningitis (CM), the optimal time to start ART is currently unclear. The high risk of mortality prior to ART and the mortality risk associated with intracranial cryptococcal IRIS need to be balanced, and published studies have shown conflicting results. ${ }^{13,14}$ The Cryptococcal Optimal ART Timing (COAT) trial was recently stopped early by the Data and Safety Monitoring Board because of excess mortality in patients who started ART in hospital $1-2$ weeks after CM diagnosis compared with those starting 5 - 6 weeks after diagnosis. The final results of this trial are awaited. In the interim, we recommend starting ART around 4 weeks after antifungal treatment (preferably amphotericin B-based) is started.

In patients with other infections (e.g. pneumocystis pneumonia or bacterial pneumonia) and who have a CD4 count $<200$ cells/ $\mu \mathrm{l}$, clinicians should aim to start ART within 2 weeks of starting treatment for that infection. In patients with severe Kaposi's sarcoma and lymphoma, ART counselling should be expedited and ART should be started as soon as possible.

Refer to supplementary material: 'Starting ART in hospital' and 'Highrisk patients'

\subsection{Patient readiness for ART}

Patient readiness for therapy is as important as the medical indications for commencing therapy.

- The patient must demonstrate insight and must have established the ability to attend reliably.

- Conventionally, ART is not started at the first visit. Usually, 2 - 3 visits staggered closely together are required before ART is started, to accommodate counselling. Prolonged delays in starting ART should be avoided. ART should be delayed only if concerns about adherence are severe enough to outweigh the risk of HIV disease progression.

- The patient should be provided with information on the following:

- ART is life-long therapy

- the importance of $100 \%$ adherence

- ART side-effects and what to do and who to contact if serious side-effects occur.

- Active depression or substance abuse should be dealt with.

- A personal treatment plan should be formulated for each patient, specifying drug storage, strategies for missed doses and how to integrate taking medication into daily routine. The patient must be made aware of scheduling in terms of clinical follow-up.

- Disclosure of HIV status (to a partner and/or other household members) should be strongly encouraged. This has been shown to be an important determinant of treatment adherence and assists in the provision of patient-directed support. Disclosure also identifies exposed contacts for screening and support. This issue needs to be handled sensitively in situations where disclosure may have harmful consequences, particularly for women.

- The patient should be encouraged to join a support group and/ or identify a treatment 'buddy'. However, neither disclosure nor support group participation are prerequisites for good adherence in all patients.

- Clinicians should ensure that they have the contact details of each patient and their treatment 'buddy'.

- Counselling should cover safe-sex practices and address issues related to reproductive health (i.e. family planning, contraception, condom use, pregnancy and PMTCT).

Refer to supplementary material: 'Common misconceptions regarding ART' and 'Adherence interventions'.

\subsection{ART in primary infection}

There is insufficient evidence to recommend ART for primary infection. There are compelling reasons to defer therapy, including lack of proven efficacy, drug toxicity, and the potential for drug resistance. Patients with severe primary infection progress more rapidly, which is an indication for careful follow-up. ART in primary infection should be considered in a properly conducted research study, or in the presence of very severe symptoms (e.g. meningo-encephalitis), which are rare. Consultation with an expert treater is advised.

\section{Initial ARV regimens for the previously untreated patient}

In accordance with international recommendations, we recommend the use of a non-nucleoside reverse transcriptase inhibitor (NNRTI) and 2 NRTIs (a safe dual NRTI combination) as the first-line ART regimen. In comparison with PIs, NNRTIs are better tolerated in the long term and are at least as potent when combined with an appropriate dual NRTI combination. ${ }^{15}$ We do not recommend PI or integrase inhibitor (integrase strand transfer inhibitor (InSTI)) use in first-line therapy, unless dictated by intolerance or NNRTI contra-indications.

Either NVP or efavirenz (EFV) may be selected as the NNRTI. EFV is the preferred NNRTI. NVP should be selected for women in the first trimester of pregnancy or those who intend to fall pregnant (section 13.2). Owing to its neuropsychiatric side-effects, EFV should be avoided in those with active psychiatric illness, shift workers and those operating heavy machinery or vehicles. NVP should be avoided in women with a CD 4 count $>250$ cells $/ \mu$ land men with a CD4 count $>400$ cells/ $\mu$ initiating ART for the first time, because of the increased risk of rash-associated hepatitis. It should be noted, however, that this sideeffect can occur at any CD4 count. Clinicians should consider avoiding NVP in patients who may encounter difficulties getting rapid medical attention should rash or hepatitis symptoms occur. NVP should also be avoided in patients with pre-existent liver disease. When both NVP and EFV are contra-indicated, raltegravir (RAL) or a PI could be substituted. Any patient starting an NNRTI should be told to report a rash, jaundice or symptoms of hepatitis immediately.

Any of the following 2-drug NRTI combinations are recommended for use with the NNRTI:

- 3TC plus TDF, AZT or ABC

- emtricitabine (FTC) - a cytidine analogue very similar to 3TC that is combined with TDF in a fixed-dose combination or with the addition of EFV as a triple-drug combination pill.

TDF is the favoured NRTI to use with 3TC (or FTC). Selection will depend on affordability and co-morbidity (e.g. patients with 
a creatinine clearance $<50 \mathrm{ml} / \mathrm{min}$ should not start TDF). If TDF is unavailable or contra-indicated, AZT should be used, provided that haemoglobin $(\mathrm{Hb})$ is $>10 \mathrm{~g} / \mathrm{dl}$. A large clinical trial comparing ABC- v. TDF-containing first-line regimens showed lower rates of virological suppression with $\mathrm{ABC}$ in patients with a baseline viral load $>100000$ copies $/ \mathrm{ml}^{16}$ Similar findings were demonstrated in a second study, ${ }^{17}$ but not confirmed in another. ${ }^{18} \mathrm{ABC}$ is more costly and unavailable in most public sector programmes and has been associated with an increased risk of myocardial infarction (MI) in some, but not all, cohort studies. ${ }^{19,20}$ The association with MI was not confirmed in a meta-analysis of RCTs. ${ }^{21}$ Nevertheless, caution is recommended when considering $\mathrm{ABC}$ for patients at significant risk of ischaemic heart disease or with established ischaemic heart disease. $A B C$ is an option to consider in chronic renal failure where TDF and AZT (because of anaemia) cannot be used.

$\mathrm{D} 4 \mathrm{~T}$ is a cheaper option than TDF, AZT and $\mathrm{ABC}$, but it is considerably more toxic. Most public sector programmes in Southern Africa have discontinued D4T in first-line ART. Nonetheless, there is still a role for $\mathrm{D} 4 \mathrm{~T}$ in selected patients, when it is used in the short term in patients with contra-indications to other NRTIs. A common example is a patient with renal dysfunction and anaemia at baseline who could be started on D4T for 3 - 6 months and then switched to AZT or TDF depending on resolution of the anaemia and/or renal dysfunction. In addition, if there is a need for concomitant nephrotoxic medications, e.g. aminoglycosides to treat multidrug resistant (MDR)-TB, D4T (or $\mathrm{AZT}$ or $\mathrm{ABC}$ ) is preferable to TDF during the period of exposure to the other nephrotoxic medication. Patients usually tolerate short-term D4T well. Severe D4T side-effects, such as hyperlactataemia, lipo-atrophy and other mitochondrial toxicity, typically occur after $4-6$ months, although peripheral neuropathy can develop earlier.

We favour regimens that include fixed-dose combinations and allow once-daily dosing (refer to Table 2 for doses and common side-effects).

\section{Laboratory monitoring for ART efficacy \\ 8.1 Viral loads}

Viral loads should be performed:

- at baseline (before commencing ART, where possible)

- at 3 months after the commencement of ART (This early viral load is desirable to detect adherence problems early before resistance develops. A small number of patients who start with a very high viral load may not be fully suppressed at 3 months despite 100\% adherence, but such patients would have had a $>2 \log$ drop in viral load from baseline; therefore, the 3-month result should be interpreted in relation to the baseline viral load. All patients who have a detectable viral load at 3 months should receive additional adherence interventions.)

- at 6 months thereafter and then every 6 months (in patients who are virologically suppressed (undetectable viral load) for longer than 12 months and who demonstrate reliable adherence and follow-up, it may be acceptable to reduce the frequency of viral load monitoring to annually)

- if viral load is $>50$ copies $/ \mathrm{ml}$, then repeat measurement in 3 months, after an adherence intervention.

\subsubsection{Notes}

(i) A viral load $>50$ copies $/ \mathrm{ml}$ while receiving ART should be an indication for urgent action to improve adherence. A subsequent ART change must be considered if there is not complete viral suppression at the subsequent 3-month follow-up viral load (see section 10 'Indications for changing ART').

(ii) Viral load monitoring is key to the success of ART. Decisions to change ART made on the basis of virological failure, rather than on clinical or immunologic failure alone, result in better patient outcomes. If the viral load is undetectable, then the virus cannot mutate and develop resistance. A sustained viral load of $<50$ copies $/ \mathrm{ml}$ is associated with the most durable virological benefit.

\subsection{CD4+ counts}

CD4 counts should be performed every 6 months. In patients being monitored with viral loads once the CD 4 count is $>200$ cells $/ \mu$ l, provided that the viral load is suppressed, routine CD4 testing could be stopped as it adds little to management. This is expert opinion rather than being evidence-based. However, if virological or clinical failure occurs, then a CD4 count should be repeated as it may influence management decisions.

\section{Defining ART failure}

In resource-limited settings where viral loads are unavailable, the WHO has devised criteria for defining ART failure on the basis of CD4 count responses or clinical disease progression. Studies have shown that switching ART regimens using these criteria results in a significant proportion of patients switching very late (with progressive accumulation of resistant mutations) and switching inappropriately (as the CD4 count response may be poor, despite optimal virological suppression). ${ }^{22}$

\subsection{Virological criteria for treatment success}

Treatment success is defined by:

- a decline in viral load of at least 2 log from pre-treatment levels 3 months after initiating ART

- a decline in viral load to $<50 \mathrm{RNA}$ copies/ml within 6 months of commencing ART and sustained thereafter.

\subsection{Virological criteria for treatment failure}

Treatment failure is defined by a confirmed HIV viral load of $>1000$ copies/ml in 2 measurements taken 1 - 3 months apart. Several factors can influence the measurement of HIV viral load. The decision to alter ART should therefore be based on the results of repeat testing after 1 - 3 months following intensive adherence counselling. Inadequate patient adherence to the prescribed regimen remains the most common reason for treatment failure. Other important causes include: prior use of single-dose NVP for PMTCT, especially when ART is initiated within 6 months of the PMTCT dose; drug interactions that decrease ART concentrations; and transmitted drug resistance, which is currently uncommon in the region $(<5 \%){ }^{23}$

\subsection{CD4 response}

Typically, the CD4 count increases rapidly in the first month of ART, by approximately $75-100 \mathrm{cells} / \mu \mathrm{l}$, with a more gradual rise thereafter $(50-100$ cells/ $\mu \mathrm{l} /$ year $){ }^{24}$ Most, but not all, patients achieve a CD4 count $>500$ cells $/ \mu 1$ after several years of ART, provided that the viral load remains suppressed. ${ }^{25-27}$ However, CD4 responses are highly variable and may fail to increase despite virological suppression, in about $10-20 \%$ of patients. ${ }^{28,29}$ Such patients have a delayed or absent CD4 response to ART despite viral suppression, which is termed an 'immunological discordant response to ART'. Certain studies suggest 
that older patients are at higher risk. There is no evidence that such patients benefit from a change in ART regimen; therefore, the same regimen should be continued. Cotrimoxazole prophylaxis should be continued if the CD4 count remains $<200$ cells/ $\mu$ and isoniazid (INH) prophylaxis should be considered. There is evidence that the prognosis of such patients is worse than in those who have a CD4 response, but better than that of patients not receiving ART. If such patients are clinically unwell, TB or lymphoma should be considered as the cause of persistent CD4 lymphopaenia.

CD4 counts may continue to rise or remain stable in the presence of incomplete viral suppression (which will result in the emergence of drug resistance) until the viral load is high (approximately 10000 copies/ml and above). ${ }^{30}$

\section{Indications for changing ART}

Individual ART drugs may be substituted in the event of toxicity (section 14), provided that the viral load is suppressed or ART was initiated within the preceding 6 months. Changing the first-line ART regimen to a second-line regimen is a major step. The drugs used in secondline regimens are often not as well tolerated and are more expensive, usually with limited options for subsequent treatment owing to cost. For this reason, clinicians tend to switch to second-line ART after a prolonged period of virological failure, which will cause a progressive increase in the accumulation of resistant mutations. This reduces the efficacy of second-line and subsequent regimens. If the viral load is $>1000$ copies $/ \mathrm{ml}$, it is essential to step up adherence interventions, as discussed above. Once the viral load is confirmed on a second specimen to be $>1000$ copies $/ \mathrm{ml}$ despite adherence, the patient should be switched to a second-line regimen without undue delay. In summary, we advise a switch to a second-line regimen when 2 viral load measurements have been $>1000$ copies $/ \mathrm{ml}$, preferably with the measurements taken 3 months apart with at least 4 weeks of an intensified adherence intervention in between. In patients with low CD 4 counts $(<100$ cells $/ \mu \mathrm{l})$, this process should be expedited.

Some patients have persistently detectable viral loads at low levels (200 - 1000 copies $/ \mathrm{ml}$ ). If patients have low level viraemia for a prolonged period ( $>1$ year) or persistently low CD4 counts $(<100$ cells/ $\mu$ l) together with low-level viraemia despite adherence interventions, they should be switched to second-line ART.

\subsection{Second-line ART}

The following ritonavir-boosted PIs are recommended in conjunction with 2 NRTIs (Table 2):

- $\mathrm{ATV} / \mathrm{r}$

- $\mathrm{LPV} / \mathrm{r}$

- $\mathrm{DRV} / \mathrm{r}$ (it is preferable to save this drug for third-line therapy, further discussed below).

Indinavir (IDV) is significantly more toxic than other PIs. SQV is less robust in terms of resistance than the 3 options listed. IDV and SQV confer no benefit over other options, and are therefore not recommended.

Boosting involves the addition of low-dose ritonavir, which inhibits PI metabolism, thereby boosting PI plasma concentration and prolonging its half-life. LPV is co-formulated with ritonavir in a heat-stable tablet (Aluvia) and is the best option in patients without a refrigerator (other PIs require ritonavir boosting with a separate ritonavir capsule that ideally requires refrigeration, although ritonavir capsules are stable at room temperature for 30 days). We recommend against the use of unboosted PIs.
If a patient was receiving a first-line combination of 2 NRTIs and a PI (boosted or unboosted), it is best to discuss the choice of second-line regimen with an experienced treater and consider a genotype resistance test. Second-line NNRTI plus NRTI regimens are often not effective in such patients because of NRTI mutations, while boosted PI regimens in second-line ART may remain effective. Decisions are therefore best guided by resistance testing.

\subsection{Selecting second-line dual NRTIs}

Because boosted PIs are robust drugs (i.e. resistance develops slowly) in PInaive patients, it is very likely that virological suppression will be achieved with good adherence, even if the 2 NRTIs used in second-line are partially compromised by NRTI resistance mutations (Tables 4 and 5). ${ }^{31}$

Certain NRTI combinations are contra-indicated for toxicity reasons (e.g. d4T plus ddI, or TDF plus ddI). TDF plus $\mathrm{ABC}$ is not recommended for second-line ART, as these agents share several resistance mutations. NRTI combinations advised for second-line regimens include either AZT plus 3TC, or TDF plus 3TC (FTC can be substituted in place of 3TC), depending on the likely mutational profile selected during the patient's first-line NRTI combination.

Even if 3TC (or FTC) is used in a failed first-line regimen and may, therefore, have selected for the M184V mutation which confers resistance to the agent, 3TC (or FTC) can be re-used in second-line therapy because of the capacity of the M184V mutation to partially restore susceptibility to AZT, $\mathrm{d} 4 \mathrm{~T}$ and TDF in the presence of thymidine analogue mutations (TAMs), and to partially restore susceptibility to TDF in the presence of the K65R mutation. The M184V mutation also reduces the replicative capacity of the virus.

Ideally, a resistance test should be performed at first-line failure to ensure that the patient does indeed have resistance (and the virus is not 'wild-type') and to guide choices of second-line and future regimens. However, in many settings in the region, this is unaffordable and/or unavailable.

\section{Patients who return after defaulting therapy}

We recommend restarting the same regimen if patients return to care after defaulting therapy and repeating HIV viral load measurements after 3 months; switching to a second-line regimen should be considered if the viral load is not suppressed at this point. If a patient is receiving first-line therapy, AZT could be substituted for D4T. However, we do not recommend substituting TDF, because, if the patient has pre-existing NNRTI and 3TC resistance, TDF resistance may rapidly result compromising its efficacy in second-line therapy. If a patient has multiple episodes of interruption, and, particularly, if they are beyond the first year of ART, then many clinicians would consider switching the patient to a second-line regimen, making the assumption that the multiple interruptions resulted in first-line resistance. Reasons for defaulting should be addressed and adherence support increased. Performing a resistance test after the patient has been off ART for longer than 4 weeks is of limited value as many resistance mutations are overtaken by wild-type when ART is stopped.

\section{Drug interactions}

There are many important drug interactions between ARV agents and other medications, as well as between certain ARV agents themselves. These interactions occur because of metabolism of ARV drugs by cytochrome $\mathrm{P} 450$ in the liver and intestine and induction or inhibition by 
Table 4. Mutations selected by first-line NRTI combinations*

\begin{tabular}{ll}
\hline First-line NRTIs & NRTI mutations selected \\
\hline 3TC or FTC & $\begin{array}{l}\text { Select for M184V, which compromises both 3TC and FTC, and slightly impairs the } \\
\text { activity of ABC and ddI, but increases susceptibility to AZT, D4T and TDF }\end{array}$ \\
& Selects for thymidine analogue mutations (TAMs) which may compromise all \\
AZT & NRTIs ${ }^{\dagger}$ \\
& Selects for TAMs which may compromise all NRTIs \\
D4T & In a minority of patients, D4T may select for K65R which compromises TDF, ABC \\
& and ddI, but increases susceptibility to AZT \\
& Selects for K65R which compromises TDF, ABC and ddI, but increases \\
TDF & susceptibility to AZT \\
& Selects for L74V which compromises ABC and ddI \\
ABC & May also select for K65R which compromises TDF, ABC and ddI, but increases \\
& susceptibility to AZT \\
& Selects for Y115F which decreases its susceptibility
\end{tabular}

Table 5. Choice of second-line NRTIs in relation to first-line NRTIs used

\begin{tabular}{ll}
\hline First-line NRTIs used & $\begin{array}{l}\text { Second-line NRTI } \\
\text { combination advised }\end{array}$ \\
\hline AZT plus 3TC & TDF plus 3TC* \\
D4T plus 3TC & $\begin{array}{l}\text { TDF plus 3TC* (preferably } \\
\text { genotype first, given the } \\
\text { increased risk of K65R on D4T } \\
\text { in subtype C) }\end{array}$ \\
& $\begin{array}{l}\text { AZT plus 3TC } \\
\text { TDF plus 3TC }\end{array}$ \\
ABC plus 3TC & AZT plus 3TC \\
*3TC is interchangeable with FTC. & \\
NRTI = nucleoside reverse transcriptase inhibitor; AZT = zidovudine; 3TC = lamivudine; D4T \\
$=$ stavudine; TDF = tenofovir; ABC = abacavir; FTC = emtricitabine.
\end{tabular}

ARVs of this and other enzyme systems and drug transporters. Certain of these drug interactions are discussed in these guidelines (e.g. the interaction between rifampicin and NNRTIs, PIs and RAL). The list of all potential drug interactions is, however, very long and therefore beyond the scope of this document. Knowledge of drug interactions is constantly evolving. Clinicians are advised to consult the package inserts of ARV agents and concomitant medication to assess for drug interactions and the following websites, which provide up-to-date information on drug interactions and the actions required to account for them:

- University of Liverpool Drug Interactions Charts: http://www.hivdruginteractions.org

- University of Cape Town Medicines Information Centre ARV interactions table: $h t t p: / / w w w . m i c . u c t . a c . z a /$ ?page_id=47

We advise that clinicians assess for potential drug interactions whenever patients start or switch to a new ARV drugs or regimens, and start new concomitant medications. In addition, herbal medications may also have interactions with ARVs.

\section{ART in special populations 13.1 TB}

The ART regimen should be modified if necessary for compatibility with rifampicin - a critical component of the TB regimen that substantially reduces the risk of relapse after completing TB treatment. EFV is the preferred NNRTI for use with rifampicin. NVP is an alternative in patients with contra-indications for EFV (e.g. psychosis), but it carries a higher risk of hepatitis and virological failure when used with rifampicin.

The plasma concentrations of all boosted PIs are reduced to subtherapeutic ranges with rifampicin. Dose adjustment of some PIs can overcome this induction (Table 6), but there is a risk of hepatotoxicity. The patient will require counselling and ALT should be monitored frequently. An alternative approach is to replace rifampicin with rifabutin. However, rifabutin is expensive and not currently available at public sector TB clinics. Also, rifabutin is not co-formulated with other TB drugs such as rifampicin, and the evidence base for rifabutin in the treatment of TB is much less substantial than that for rifampicin. ${ }^{33}$ There is also uncertainty regarding the optimal dose of rifabutin with boosted PIs; current guidelines recommend $150 \mathrm{mg}$ on alternate days. Rifabutin may be considered in patients not tolerating co-treatment with ART and rifampicin-based antitubercular therapy (e.g. patients unable to tolerate the increased LPV/r dose) or in ARTexperienced patients on an ART regimen that is not compatible with rifampicin (e.g. those on third-line ART with DRV/r). Rifabutin doses may require adjustment (Table 8). If rifabutin is unavailable and adjusted doses of PIs are poorly tolerated in patients on second-line ART, double-dose RAL (800 mg 12-hourly) may be substituted for the PI or triple NRTI therapy may be considered. Triple NRTI ART is, however, inferior to conventional ART and RAL is less robust than a PI in second-line therapy. Nevertheless, short-term use over 6 months is probably preferable to treating TB without rifampicin, which has a high risk of failure or relapse. ART and TB medication share many side-effects (Table 7). 
Table 6. ART interactions with rifampicin and recommendations for co-administration

\begin{tabular}{|c|c|c|c|}
\hline Class & ARV agent & Interaction & Dose of ART drug with rifampicin \\
\hline NRTIs & All in class & No significant pharmacokinetic interactions & No dose adjustment required \\
\hline \multirow[t]{3}{*}{ NNRTIs } & EFV & $\begin{array}{l}\text { Mild reduction in EFV concentrations } \\
\text { In some patients, EFV concentrations may } \\
\text { increase }\end{array}$ & No dose adjustment required (600 mg nocte) \\
\hline & NVP & Moderate reduction in NVP concentrations & $\begin{array}{l}\text { Use standard dosing, but omit the lead-in dose phase and } \\
\text { start } 200 \mathrm{mg} \text { NVP 12-hourly }\end{array}$ \\
\hline & ETV & Marked reduction in ETV concentrations & Do not prescribe concomitantly \\
\hline \multirow[t]{3}{*}{ PIs } & $\mathrm{LPV} / \mathrm{r}$ & $\begin{array}{l}\text { LPV plasma concentrations significantly } \\
\text { decreased }\end{array}$ & $\begin{array}{l}\text { The preferable strategy is to double the dose of LPV/r to } \\
800 / 200 \mathrm{mg} 12 \text {-hourly } \\
\text { Alternatively, add } 300 \mathrm{mg} \text { ritonavir } 12 \text {-hourly to standard } \\
\text { dose of } 2 \text { tablets } 12 \text {-hourly of LPV/r } \\
\text { There is an increased risk of hepatotoxicity with these } \\
\text { strategies } \\
\text { These dose adjustments can be made gradually over } 1 \text { - } 2 \\
\text { weeks* }\end{array}$ \\
\hline & $\mathrm{SQV} / \mathrm{r}$ & $\begin{array}{l}\text { SQV concentrations are significantly } \\
\text { decreased }\end{array}$ & $\begin{array}{l}400 \mathrm{mg} \text { SQV plus } 400 \mathrm{mg} \text { ritonavir 12-hourly } \\
\text { Increased risk of hepatotoxicity }\end{array}$ \\
\hline & All other PIs & Marked reduction in PI concentrations & Do not prescribe concomitantly \\
\hline InSTI & RAL & Marked reduction in concentrations & Double the dose of RAL to $800 \mathrm{mg}$ 12-hourly \\
\hline
\end{tabular}

${ }^{*}$ The double dosing regimen is preferred as it is better tolerated. Dose adjustments should be continued for 2 weeks after rifampicin is stopped.

$\mathrm{ART}=$ antiretroviral therapy; $\mathrm{ARV}=$ antiretroviral; $\mathrm{NRTI}=$ nucleoside reverse transcriptase inhibitor; $\mathrm{NNRTI}=$ non-nucleoside reverse transcriptase inhibitor; $\mathrm{PI}=$ protease inhibitor; InSTI $=$ Integrase inhibitor (integrase strand transfer inhibitor); EFV = efavirenz; NVP = nevirapine; LPV = lopinavir; LPV/r = lopinavir/ritonavir; SQV = saquinavir; SQV/r $=$ saquinavir/ritonavir; $\mathrm{RAL}=\mathrm{raltegravir}$.

Table 7. Shared side-effects of TB treatment and ART

\begin{tabular}{lll}
\hline Side-effects & ART & TB treatment \\
\hline Nausea & AZT, ddI, PIs & Pyrazinamide, ethionamide \\
Hepatitis & NVP, EFV, PIs & Rifampicin, isoniazid, pyrazinamide and many second-line \\
& (NRTIs can cause steatohepatitis $)$ & drugs including quinolones \\
Peripheral neuropathy & D4T, ddI & Isoniazid, ethionamide, terizidone/cycloserine \\
Renal impairment & TDF & Aminoglycosides \\
Rash & NVP, EFV, RAL & Rifampicin, isoniazid, pyrazinamide, ethambutol, streptomycin \\
& & and many second-line drugs including quinolones \\
Neuropsychiatric & EFV & Terizidone/cycloserine, quinolones, isoniazid
\end{tabular}

Table 8. Dosing of ARVs and rifabutin when prescribed concomitantly

\begin{tabular}{lll}
\hline ARV & $\begin{array}{l}\text { ARV dose } \\
\text { change }\end{array}$ & Rifabutin dose \\
\hline EFV & None & $\begin{array}{l}\text { Increase to } 450 \\
\mathrm{mg} / \text { day }\end{array}$ \\
NVP & None & $300 \mathrm{mg} /$ day \\
ATV & None & $\begin{array}{l}\text { Decrease to } 150 \mathrm{mg} \\
\text { every second day }\end{array}$ \\
ritonavir-boosted PIs & &
\end{tabular}

$\mathrm{ARV}=$ antiretroviral; $\mathrm{EFV}=$ efavirenz; $\mathrm{NVP}=$ nevirapine; $\mathrm{ATV}=$ atazanavir; $\mathrm{PI}=$ protease inhibitors.

\subsection{Pregnancy}

AIDS is the most frequent cause of death in pregnant women in many Southern African countries, ${ }^{34}$ and is a significant cause of morbidity and mortality in children born to HIV-infected women. Even where children are born HIV-negative, their mortality is significantly increased. Traditionally, the focus on HIV and pregnancy has centred on the transmission of HIV to children. This has lead to complex regimens to address concerns about efficacy and resistance. These guidelines attempt where possible to simplify this approach, to decrease transmission in both pregnant and breastfeeding mothers, and facilitate the continuum of care.

\subsubsection{NNRTI and PI choice in pregnancy}

- EFV has been shown to be teratogenic in primates, resulting in craniofacial abnormalities in exposed offspring. There have been 
isolated human case reports of myelomeningocele (neural tube defects) in infants following intra-uterine exposure to EFV. The drug is classified by the United States Food and Drug Administration (FDA) as a category D drug, meaning that 'there is positive evidence of human fetal risk, but the benefits from use in pregnant women may be acceptable despite the risk (e.g. if the drug is needed in a lifethreatening situation or for a serious disease for which safer drugs cannot be used or are ineffective).'

- It should be noted, however, that data supporting this classification are not definitive. The incidence of neural tube defects and all congenital abnormalities among women exposed to EFV in the first trimester is similar to that of the general population, but insufficient numbers have been studied to state definitively that the drug is safe. ${ }^{35}$ Most experts are willing to prescribe EFV for use in the second and third trimester, because the neural tube is formed in the first 4 weeks of pregnancy. If a woman expresses the desire to fall pregnant, we suggest starting an alternative to EFV or switching from EFV to an alternative. However, if a woman falls pregnant on EFV we suggest continuing it (the neural tube forms in the first 4 weeks). In a pregnant woman not yet receiving ART, we suggest starting ART after the first trimester so that EFV can be used, unless the patient has advanced immunosuppression, in which case NVP can be started in the first trimester. Recent guidance from WHO is that EFV can be used throughout pregnancy; their review of current data on EFV safety and risk of teratogenicity was reassuring and, from a public health perspective, the need for simplicity and the toxicity associated with NVP were considered to outweigh concerns regarding unproven risks associated with $\mathrm{EFV}^{36}$

- NVP-based ART is the preferred regimen for women in the first trimester of pregnancy. Initiating NVP at a CD4 count $>250$ cells $/ \mu \mathrm{l}$ is associated with a much higher risk of rash-associated hepatitis. It should be noted that switching to NVP in women who plan to fall pregnant with CD4 counts that have increased to $>250$ cells $/ \mu \mathrm{l}$ on ART is not associated with this increased risk. Nevertheless, a background risk of rash and hepatitis remains.

- In women who are wanting to fall pregnant if the CD4 count is $>250$ cells/ $\mu \mathrm{l}$, or if there is intolerance to NVP, a boosted PI regimen can be used instead of NVP. Studies have shown that LPV concentrations are significantly reduced in pregnancy, but are adequate provided that LPV is the first PI that has been used. Once-daily dosing of $\mathrm{LPV} / \mathrm{r}$ should not be used in pregnancy. Similarly, concentrations of boosted ATV are reduced in pregnancy, and the dose of ATV should be increased to $400 \mathrm{mg}$ daily with $100 \mathrm{mg}$ ritonavir daily. Unboosted ATV is not recommended in pregnancy.

\subsubsection{General points}

- Fertility choices in the context of HIV treatment are complex. Clinicians should check these choices at every patient visit to minimise risks. Adequate access to safe and effective contraception should be provided. For further guidance:

Southern African HIV Clinicians Society. Guideline on safer conception in fertile HIV-infected individuals and couples. Southern African Journal of HIV Medicine 2011;12:31-44.

- Clinicians should be aware that women may fall pregnant unintentionally, but that the response may still vary from welcoming the pregnancy to wanting a termination.
- In general, far too few women in the Southern African region receive prophylaxis for PMTCT. Every effort must be made to ensure rapid ascertainment of HIV status and access to appropriate PMTCT and ART.

- South African data suggest that most HIV transmissions to babies occur from HIV-positive mothers with CD4 counts $<350$ cells/ $\mu$ l. Rapid ART initiation for the mother at this level will have a large effect on both maternal and child health.

- All pregnant women of unknown HIV status or who were previously HIV-negative should be offered an HIV test, irrespective of previous sexual activity, marital status, social group or perceived HIV risk status. Ideally, testing should be repeated in the last trimester, as some studies have suggested a greater HIV acquisition risk during pregnancy.

- Mother-to-child transmission is a rapidly evolving field, and international guidelines should be monitored for major changes.

\subsubsection{Recommendations}

For women who are pregnant and not receiving ART, the following is recommended as best standard of care in situations where resources are available:

- All pregnant women should be initiated on triple-drug ART, if adequately prepared, irrespective of CD4 cell count and viral load.

- HIV testing and staging must be done quickly and ART adherence counselling should be accelerated, with the aim to put women on treatment within 2 weeks of first visit (and more rapidly in the third trimester of pregnancy). Women who are being initiated onto ART for PMTCT should ideally be initiated after the first trimester, but women with a CD 4 count $<200$ cells/ $\mu$ l or with severe HIV morbidity should be started in the first trimester.

- Women with baseline CD4 counts $<350$ cells/ $\mu$ l should have their ART continued indefinitely.

- Women who elect to breastfeed and have a baseline CD4 count $>350$ cells $/ \mu$ should continue ART until weaning has occurred.

- ART should be stopped after delivery in women with baseline CD4 counts $>350$ cells $/ \mu$ l, provided that they are formula feeding.

- If a woman presents during labour and is not receiving ART, singledose NVP should be given to mother and baby, with additional AZT and 3TC for 1 week or single-dose TDF/FTC to the mother to reduce the risk of NNRTI resistance developing (NVP has a very long half-life).

- Refer to PMTCT guidelines for recommended regimens for the baby.

\subsection{ARV dosages in renal failure (Table 9)}

Renal function is estimated either by the modified Cockgraft-Gault equation (see Table 9) or the modification of diet in renal disease (MDRD) method, which most laboratories report as 'e-GFR'. The results of these formulae differ slightly, but either can be used for clinical management.

For peritoneal dialysis, the dose given with a creatinine clearance $<10$ should be given daily. For haemodialysis, the dose given with a creatinine clearance $<10$ should be given daily, but must be given after dialysis on dialysis days, to prevent the drug from be dialysed out.

\subsection{ARV dosages in liver impairment}

Unlike in renal impairment, there is no blood test that can accurately quantify liver impairment. Child-Pugh class C may require dose 
adjustment for the relevant ARVs listed in Table 10. In general, the combination of TDF with 3TC (or FTC) and EFV (or RAL) is regarded as the least hepatotoxic. If the patient has active hepatitis $\mathrm{B}$, discontinuation of ARVs that have activity against hepatitis B (TDF, 3TC and FTC) can cause severe flares of hepatitis (see section 13.5).

\subsection{Hepatitis B co-infection}

Hepatitis B is a common co-infection in Southern Africa with HIV, with significant implications for progression to cirrhosis, as well as for treatment options. Clinicians are encouraged to support current efforts in the region to vaccinate all children for hepatitis B, and to extend coverage to eligible adults. Access to vaccination, laboratory resources and treatment options are all limited to some extent in Southern African countries, and the recommendations below should each be considered in the light of the local context.

All HIV-infected patients should be screened for active hepatitis B (limiting screening to those with liver function abnormalities will miss many cases as liver enzymes are often normal in hepatitis B infection). Hepatitis B surface antigen is an appropriate screening test. Hepatitis B DNA viral load correlates with disease progression and may be used to monitor anti-hepatitis B therapy, but it is expensive and availability is limited.

Hepatitis B/HIV co-infection is associated with:

- an increased risk of chronic liver disease

- a higher hepatitis B viral load

- diminished responses to hepatitis B vaccine

- poorer responses to interferon-alpha treatment

- an increased incidence of drug-induced hepatotoxicity (particularly with NVP)

\section{Table 9. ARV dosage adjustments in renal failure}

\begin{tabular}{|c|c|c|}
\hline \multirow[b]{2}{*}{ Drug } & \multicolumn{2}{|c|}{ Creatinine clearance } \\
\hline & $10-50$ & $<10$ \\
\hline $\mathrm{AZT}$ & Unchanged & $300 \mathrm{mg}$ daily \\
\hline ddI & $\begin{array}{l}>60 \mathrm{~kg} \text { body weight: } \\
200 \mathrm{mg} \text { daily } \\
<60 \mathrm{~kg} \text { body weight: } \\
150 \mathrm{mg} \text { daily }\end{array}$ & $\begin{array}{l}>60 \mathrm{~kg} \text { body weight: } \\
100 \mathrm{mg} \text { daily } \\
<60 \mathrm{~kg} \text { body weight: } \\
75 \mathrm{mg} \text { daily }\end{array}$ \\
\hline $3 \mathrm{TC}$ & $150 \mathrm{mg}$ daily & $50 \mathrm{mg}$ daily \\
\hline $\mathrm{D} 4 \mathrm{~T}$ & 15 mg 12-hourly & 15 mg daily \\
\hline $\mathrm{ABC}$ & Unchanged & Unchanged \\
\hline TDF & AVOID & AVOID \\
\hline PIs & Unchanged & Unchanged \\
\hline NNRTIs & Unchanged & Unchanged \\
\hline \multicolumn{3}{|c|}{$\begin{array}{l}\text { *Source: Bartlett JG. Medical care of patients with HIV Infection 2010, and The Sanford guide to } \\
\text { Antimicrobial Therapy } 2010 .\end{array}$} \\
\hline \multicolumn{3}{|c|}{$\begin{array}{l}\mathrm{AZT}=\text { zidovudine; } \mathrm{ddI}=\text { didanosine; } 3 \mathrm{TC}=\text { lamivudine; } \mathrm{D} 4 \mathrm{~T}=\text { stavudine; } \mathrm{ABC}=\text { abacavir; } \\
\mathrm{TDF}=\text { tenofovir; } \mathrm{PI}=\text { protease inhibitor; } \mathrm{NNRTI}=\text { non-nucleoside reverse transcriptase } \\
\text { inhibitor. }\end{array}$} \\
\hline \multicolumn{3}{|c|}{ The modified Cockgraft-Gault equation: } \\
\hline \multicolumn{3}{|c|}{ creatine clearance $^{*}=\frac{(140-\text { age }) \times \text { ideal weight }}{\text { serum creatinine }}$} \\
\hline${ }^{*}$ For women & he total by 0.85 . & \\
\hline
\end{tabular}

- a flare of hepatitis within 3 months of commencing ART (due to hepatitis B-IRIS, which is difficult to differentiate from drug hepatotoxicity).

Drugs directed against hepatitis B that have no or minimal antiHIV activity (e.g. entecavir and telbivudine) are largely unavailable or extremely expensive in our region. For practical purposes, the only available therapy is to use ARVs that also have anti-hepatitis B activity (TDF, 3TC and FTC). As with HIV, these drugs suppress hepatitis B, but do not eradicate it. Effective treatment prevents or slows progression to cirrhosis.

Indications for specific hepatitis B treatments ${ }^{37}$ include any one of the following:

- a positive test for hepatitis $B$ e antigen

- raised ALT ( $>2 \mathrm{x}$ the upper limit of normal (ULN))

- evidence of fibrosis on biopsy or on appropriate imaging

- a hepatitis B viral load $>10000$ copies/ml (or $2000 \mathrm{IU} / \mathrm{ml}$ ).

If any of the above criteria are met, then ART should be commenced irrespective of the CD4 count. The ART regimen should include TDF and 3TC (or FTC). Using 3TC without including TDF leads to hepatitis B resistance in $80-90 \%$ of patients after 5 years of treatment. If patients meet criteria for switching to a second-line ART regimen (to treat their HIV), this combination (TDF and 3TC/FTC) should be continued to suppress HBV infection, as interruption of TDF and/or FTC/3TC has been associated with life-threatening hepatitis flares. The second-line ART regimen should be shaped around these 2 drugs in discussion with an experienced treater. NVP should be avoided in patients with hepatitis B co-infection.

In patients with hepatitis B and renal dysfunction, the use of TDF may be considered with dosing frequency adjustment based on creatinine clearance (see package insert) and more frequent creatinine monitoring. If renal dysfunction is severe or renal function deteriorates with TDF, 3TC monotherapy (with or without pegylated interferon-alpha) should be considered. Pegylated interferon-alpha is very costly. For further guidance:

Southern African HIV Clinicians Society. Management of HIV-hepatitis B co-infection. Southern African Journal of HIV Medicine 2011;12:27-33.

\subsection{Malaria}

There are several drug interactions between antimalarials and ARVs:

- Artemether-lumefantrine (Coartem) can be safely administered with NVP. There are no data yet on interactions with EFV, but the combination is likely to be safe. Boosted PIs dramatically increase the plasma concentrations of lumefantrine, but a dose reduction is not recommended, as the toxicity threshold of lumefantrine seems to be high. Close monitoring for toxicity is recommended when co-administering artemether-lumefantrine with ART.

- Quinine concentrations are significantly decreased by LPV/r, probably due to induction of metabolism by ritonavir. It is likely that quinine concentrations will also be reduced by EFV and NVP; therefore, quinine should be avoided in patients receiving PIs or NNRTIs. Patients with severe malaria should receive artesunate and those with milder malaria should be treated with artemetherlumefantrine.

- Among drugs used for chemoprophylaxis, there are no clinically significant pharmacokinetic interactions between ARVs and mefloquine or doxycycline. However, mefloquine and EFV both 
Table 10. Prescribing ARVs in liver impairment

\begin{tabular}{|c|c|c|}
\hline Class & Drug & Prescribing notes \\
\hline \multirow[t]{7}{*}{ NRTIs } & $\mathrm{ABC}$ & $\begin{array}{l}\text { Reduce adult dose to } 200 \mathrm{mg} \text { bd for significant liver impairment } \\
\text { Contra-indicated in severe hepatic impairment }\end{array}$ \\
\hline & ddI & $\begin{array}{l}\text { Use with caution: recent reports implicate use as a risk factor for the development of hepatic } \\
\text { decompensation in patients being treated for cirrhosis due to hepatitis C }\end{array}$ \\
\hline & FTC & $\begin{array}{l}\text { In patients with chronic hepatitis B, there is a risk of rebound hepatitis when FTC is discontinued or if } \\
\text { hepatitis B resistance to FTC develops }\end{array}$ \\
\hline & $3 \mathrm{TC}$ & $\begin{array}{l}\text { In patients with chronic hepatitis B, there is a risk of rebound hepatitis when } 3 \mathrm{TC} \text { is discontinued or if } \\
\text { hepatitis B resistance to } 3 \mathrm{TC} \text { develops }\end{array}$ \\
\hline & $\mathrm{D} 4 \mathrm{~T}$ & Use with caution and never combine $\mathrm{D} 4 \mathrm{~T}$ and ddI in patients with liver disease \\
\hline & TDF & In patients with chronic hepatitis $\mathrm{B}$, there is a risk of rebound hepatitis when TDF is discontinued \\
\hline & AZT & Decrease dose by $50 \%$ or double dosage interval if significant liver disease \\
\hline \multirow[t]{2}{*}{ NNRTIs } & EFV & $\begin{array}{l}\text { Caution should be exercised in administering EFV to patients with liver disease } \\
\text { Therapeutic drug monitoring should be done if available }\end{array}$ \\
\hline & NVP & Avoid if significant hepatic impairment or active hepatitis B or C \\
\hline \multirow[t]{5}{*}{ PIs } & ATV & Avoid in severe hepatic impairment \\
\hline & IDV & Reduce unboosted adult dose to $600 \mathrm{mg} 8$-hourly if significant hepatic impairment \\
\hline & $\mathrm{LPV} / \mathrm{r}$ & $\begin{array}{l}\text { LPV is highly metabolised in the liver and concentrations may be increased in patients with hepatic } \\
\text { impairment } \\
\text { Therapeutic drug monitoring should be done if available }\end{array}$ \\
\hline & DRV & Use with caution or avoid if significant liver disease \\
\hline & SQV & $\begin{array}{l}\text { Avoid: there have been reports of worsening liver disease and development of portal hypertension after } \\
\text { starting SQV in patients with severe liver disease }\end{array}$ \\
\hline
\end{tabular}

cause frequent neuropsychiatric side-effects; therefore, doxycycline is the preferred chemoprophylactic agent for patients receiving EFV.

- There are several interactions with atovaquone-proguanil (Malanil). Atovaquone concentrations are reduced by PIs and EFV. It is also likely that NVP decreases atovaquone concentrations. Proguanil concentrations are also reduced by PIs and EFV. Use of atovaquoneproguanil is therefore best avoided in patients receiving PIs or NNRTIs.

\section{ARV toxicity monitoring and management}

Currently used ART is generally well tolerated. Many adverse drug reactions are mild and occur only in the first few weeks of therapy. If toxicity does not resolve or is severe, then the offending drug should be substituted as indicated below. It is important to ensure that the viral load is suppressed before substituting a single drug, otherwise resistance may develop to the new drug, consequently compromising future regimens. Single drug substitutions can be performed safely in the first 6 months of ART without measuring the viral load.

It is rarely necessary to stop the entire ART regimen due to toxicity. It is advised to switch only the culprit drug and continue the rest of the ART regimen. In certain life-threatening situations (e.g. hepatitis with liver failure, lactic acidosis), it may be necessary to cease use of all ARVs. In patients with severe NNRTI-related toxicity, a PI should be substituted. If this is undesirable (e.g. in a patient receiving TB therapy), use of the NNRTI should be stopped and 2 NRTIs should be continued for 1 week to reduce the risk of resistance developing to NNRTIs, which have a long half-life.

\subsection{Haematological toxicity}

Cytopaenias occur commonly in HIV infection without exposure to ART. Patients receiving AZT, D4T or cotrimoxazole may experience abnormalities in their FBCs. Significant bone marrow toxicity from cotrimoxazole generally only occurs with high doses used for treating opportunistic infections. Patients receiving prophylactic cotrimoxazole uncommonly develop isolated neutropaenia. FBC monitoring is necessary with AZT; this should be performed monthly for 3 months, then after 6 months of therapy and thereafter if clinically indicated (it is unusual to see haematological toxicity occurring after 6 months). The main problem arising from AZT use is anaemia and neutropaenia; platelet counts generally rise with use of the drug. Management guidelines are provided in Table 11. Macrocytosis is usual with D4T and AZT therapy; there is no need to measure vitamin $B_{12}$ and folate concentrations, unless there are other indications that these may be deficient.

Pure red cell aplasia, which presents with severe anaemia and low reticulocyte index, has rarely been associated with 3TC. A bone marrow examination should be performed to confirm the condition. Parvovirus B19 infection should be excluded (a polymerase chain reaction (PCR) test should be requested on blood sent in an ethylenediaminetetraacetic acid (EDTA) tube).

\subsection{Hepatotoxicity}

- Liver function tests (LFTs) should be performed at ART initiation and measurement interval should be tailored thereafter to individual drug regimens. The full panel of LFTs is expensive; therefore, it 
Table 11. Guidelines for managing haematological toxicity (mainly AZT-induced)

\begin{tabular}{|c|c|c|c|c|}
\hline $\mathrm{Hb}$ & $\begin{array}{l}>8 \mathrm{~g} / \mathrm{dl} \\
\text { Monitor }\end{array}$ & $\begin{array}{l}7.0 \text { - } 7.9 \\
\text { Repeat } 4 \text { weeks } \\
\text { Reduce AZT } \\
200 \text { mg bd or consider } \\
\text { switching AZT }\end{array}$ & $\begin{array}{l}6.5 \text { - } 6.9 \\
\text { Repeat } 2 \text { weeks } \\
\text { Consider switching AZT }\end{array}$ & $\begin{array}{l}<6.5 \\
\text { Switch AZT }\end{array}$ \\
\hline Neutrophils & $\begin{array}{l}1-1.5 \times 10^{9} / 1 \\
\text { Repeat } 4 \text { weeks }\end{array}$ & $\begin{array}{l}0.75-1.0 \\
\text { Repeat } 2 \text { weeks }\end{array}$ & $\begin{array}{l}0.50 \text { - } 0.75 \\
\text { Repeat } 2 \text { weeks } \\
\text { Consider switching AZT }\end{array}$ & $\begin{array}{l}<0.5 \\
\text { Switch AZT }\end{array}$ \\
\hline
\end{tabular}

Table 12. Guidelines for managing hepatotoxicity

\begin{tabular}{|c|c|c|c|}
\hline ULN $^{*}$ & $<2.5 \times$ ULN & $2.5-5 \times$ ULN & $>5 \times$ ULN \\
\hline ALT & Monitor & Repeat at 1 week & Discontinue relevant drug(s) \\
\hline ALP & Monitor & Repeat at 2 weeks & $\begin{array}{l}\text { Ultrasound } \\
\text { Consider biopsy }\end{array}$ \\
\hline Bilirubin & Repeat at 1 week & Discontinue relevant drug(s) & Discontinue relevant drug(s) \\
\hline
\end{tabular}

is recommended that only ALT is monitored, as this is the most sensitive indicator of drug-induced liver injury. The full LFT profile should be requested in patients with symptoms suggestive of hepatitis. All ARV classes have been associated with hepatotoxicity most commonly NNRTIs. The NRTIs very rarely present with acute hepatitis. Mild ALT elevations occur very commonly and usually transiently with many drugs in general. ALT elevations $>5 \mathrm{xULN}$ are significant.

- Ideally, in patients starting NVP, ALT should be monitored at 2, 4, 8 and 12 weeks after initiation. If monitoring is performed, a system should be in place to obtain the result and contact the patient; routine ALT monitoring makes little sense in settings where the result will only be available when the patient is seen in 2 - 4 weeks, or where the patient cannot be contacted. It is essential to educate all patients starting NVP about the symptoms of hepatitis (nausea, vomiting, anorexia, malaise, jaundice and right upper quadrant pain) and drug rash, which is frequently associated with hepatitis. If such symptoms develop, ALT should be determined urgently.

- Hepatotoxic drugs should be discontinued at high levels of LFT abnormality (Table 12) or at lower levels if any symptoms of hepatitis appear. Rechallenge may be considered in selected cases; a specialist should be consulted. If hepatitis occurs together with a rash or fever, or with other systemic involvement, then rechallenge with NNRTIs, ABC or cotrimoxazole should not be attempted.

- Prolonged use of NRTIs, especially D4T and ddI, may cause fatty liver. Typically, ALT concentration is more signficantly elevated than AST, and the concentration of cannalicular enzymes (GGT and alkaline phosphatase (ALP)) is more significantly elevated than the transaminases. Non-tender hepatomegaly may be present. Ultrasound or computed tomography (CT) imaging may show decreased hepatic density. The condition is not benign and fibrosis has been reported with long-term ddI use. Patients should be advised to avoid alcohol. Patients receiving d4T or ddI should be switched to safer NRTIs.
- In patients with severe hepatitis or jaundice, the international normalised ratio (INR) should be assessed, as well as features of hepatic encephalopathy (i.e. features of hepatic failure).

- If the concentration of cannalicular enzymes is more significantly elevated than ALT, or if conjugated bilirubin is elevated, an ultrasound of the liver should be conducted to exclude biliary obstruction.

- Isolated unconjugated hyperbilirubinaemia (drug-induced Gilbert's syndrome) is associated with certain PIs (IDV and especially ATV). Although this is a benign condition, it is often cosmetically unacceptable to patients.

- Patients with underlying hepatitis B or C infection frequently experience a 'flare' of hepatitis when ART is commenced, as a consequence of IRIS. Hepatitis B can also flare when ARVs that have activity against hepatitis B (TDF, 3TC and FTC) are discontinued or when hepatitis $\mathrm{B}$ resistance develops.

- Many other drugs can cause hepatotoxicity, notably anti-TB agents (including prophylactic isoniazid) and azoles. Cotrimoxazole is a rare cause of hepatitis, usually with a cholestatic picture.

\subsection{Hyperlactataemia}

- This side-effect has become less common with fewer patients starting ART with D4T and with the use of lower doses. However, clinicians should remain vigilant in patients receiving D4T and be aware that this side-effect can occur with all other NRTIs, although very rare with $\mathrm{ABC}, \mathrm{TDF}, 3 \mathrm{TC}$ and FTC. Mildly elevated lactate is not uncommon in patients treated with NRTIs, but is generally asymptomatic. Asymptomatic elevated lactate does not predict the

The potential of NRTIs to cause elevated lactate varies (from most likely to least likely):

stavudine/didanosine $>$ zidovudine $>$ tenofovir/emtricitabine/ lamivudine/abacavir 
development of lactic acidosis; it is therefore unnecessary to monitor levels in asymptomatic patients.

- Lactic acidosis is a serious, rare, potentially fatal side-effect of NRTIs, most commonly associated with D4T, particularly when combined with ddI. Symptomatic hyperlactataemia without acidosis is more common, but seldom seen with the safer NRTIs recommended.

- The combination of D4T and ddI is associated with a high risk of symptomatic hyperlactactaemia or lactic acidosis (particularly in pregnancy). This combination should therefore be avoided.

- Symptoms are non-specific and include nausea and vomiting, abdominal pain, dyspnoea, fatigue and weight loss.

- Risk factors for hyperlactataemia include:

- female gender

- obesity

- the use of NRTIs for $>6$ months

- the development of NRTI-induced peripheral neuropathy or fatty liver.

- A raised lactate of $>5 \mathrm{mmol} / \mathrm{l}$ together with metabolic acidosis confirms the diagnosis of lactic acidosis. Low serum bicarbonate $(<20 \mathrm{mmol} / \mathrm{l})$ is the most sensitive marker of acidosis. Associated abnormalities include elevated AST and ALT, lactate dehydrogenase and creatinine kinase. Treatment is supportive. High-dose riboflavin $(50 \mathrm{mg}$ ) and L-carnitine may be used (no evidence for either intervention). Management depends on the lactate and bicarbonate concentrations:

- Lactate $<5 \mathrm{mmol} / \mathrm{l}$ and bicarbonate $>20 \mathrm{mmol} / \mathrm{l}$ and minor symptoms. NRTIs should be switched to agents less associated with hyperlactataemia: TDF or ABC (if these are unavailable, then AZT could be used) plus FTC or 3TC. Symptoms and serial lactate should be monitored for several months (lactate levels decrease slowly over weeks).

- Lactate $>\mathbf{5} \mathbf{~ m m o l} / \mathrm{l}$ and bicarbonate $>\mathbf{1 5} \mathbf{~ m m o l} / \mathrm{l}$. NRTIs should be discontinued and the patient should be admitted. If the patient is on an NNRTI regimen, a boosted PI should be added. If the patient has already failed an NNRTI and is on a boosted PI, RAL and/or etravirine (ETV) should be added, if available, or the patient should be continued on the boosted PI only. When lactate has normalised, the patient should be switched to TDF or $\mathrm{ABC}$ with 3TC or FTC, as above.

- Lactate $>\mathbf{5 m m o l} / \mathbf{l}$ and bicarbonate $<\mathbf{1 5} \mathbf{~ m m o l} / \mathbf{l}$. NRTIs should be discontinued and the patient should be admitted, preferably to an intensive care unit. If the patient is on an NNRTI regimen, a boosted PI should be added. If the patient has already failed an NNRTI regimen and is receiving a boosted PI, RAL and/or ETV should be added, if available, or the patient should be continued on a boosted PI only. Bicarbonate replacement is controversial, but most experts would use this strategy to partially correct severe acidosis. Broad-spectrum antibiotics are recommended as sepsis can mimic NRTI-induced lactic acidosis (this can be discontinued if procalcitonin is normal). On recovery, all NRTIs should be avoided in future regimens (some experts would be prepared to use safer NRTIs, as above).

For further guidance:

Southern African HIV Clinicians Society. Guidelines for the prevention, diagnosis and management of NRTI-associated symptomatic hyperlactataemia and lactic acidosis. Southern African Journal of HIV Medicine 2006;7:8-15.

\subsection{Dyslipidaemia}

- PIs, with the exception of unboosted ATV, can cause fasting hypertriglyceridaemia and elevated LDL-cholesterol. Boosted ATV is associated with less severe dyslipidaemia. D4T can cause mild hypertriglyceridaemia. PIs are associated with the most marked elevation of triglycerides. EFV can cause elevated total cholesterol and mild hypertriglyceridaemia.

- Diet and lifestyle modification should always be advised. Diet is more effective for controlling hypertriglyceridaemia than hypercholesterolaemia. Other cardiovascular risk factors should be addressed.

- If patients receiving PIs develop dyslipidaemia that warrants lipidlowering therapy, they should be switched to boosted ATV, if possible, rather than adding therapy for the dyslipidaemia. Switching the PI to RAL is another option, because RAL has a favourable lipid profile. However, RAL should only be used in a regimen with 2 other fully active drugs.

- Marked hypertriglyceridaemia (>10 mmol/l) can cause pancreatitis and requires urgent treatment with diet, fibrates and switching to boosted ATV (fibrates can be stopped after 1 month followed by reassessment). Indications for statin therapy in HIV-infected patients should be the same as in uninfected patients, according to the Framingham heart disease risk score. Many statins have interactions with PIs that can lead to potentially toxic statin concentrations, with the exception of pravastatin and fluvastatin, which can be used without dose adjustment. Atorvastatin concentrations are significantly raised by PIs, but lower doses (e.g. $10 \mathrm{mg}$ daily) can be used. Lovastatin and simvastatin should not be co-administered with PIs, as their concentrations are dramatically increased and severe rhabdomyolysis has been reported.

- We suggest assessing lipids after 3 months on a PI regimen. If normal at this stage, the assessment should be performed annually only in those with other cardiovascular risk factors.

\subsection{Lipodystrophy}

- Long-term ART use may cause chronic lipodystrophic changes, with a change in body fat distribution. This can present with fat accumulation (visceral obesity, breast enlargement, 'buffalo hump' or lipomata) or fat loss (lipo-atrophy, presenting as facial, limb and buttock wasting) or with both.

- The thymidine analogue NRTIs (AZT and especially D4T) are associated with fat loss.

- Previously, PIs were thought to be the cause of lipohypertrophy. However, more recent studies have shown that all classes of ARVs are associated with fat gain to the same extent. Furthermore, longitudinal studies comparing HIV-uninfected people with HIVinfected people on long-term ART have demonstrated that the extent and distribution of fat gain are similar. These data suggest that fat gain is a consequence of treating HIV. The appearance of the fat gain is particularly unsightly when accompanied by subcutaneous fat loss.

- The re-distribution of body fat may be cosmetically unacceptable to the patient, resulting in discontinuation of ART.

- Lipo-atrophy improves when D4T/AZT is substituted with TDF or $\mathrm{ABC}$, but resolution is very slow and usually incomplete; therefore, it is important to recognise lipo-atrophy early or, better still, to use NRTIs that are not associated with the condition. 
- There is no good evidence to support the switching of ARVs in patients with fat accumulation. Exercise is of some assistance in reducing abdominal fat. Surgery should be considered in selected cases with focal fat gain (e.g. those with prominent 'buffalo humps'). Metformin modestly reduces weight and improves insulin resistance in patients with the metabolic syndrome or isolated dysglycaemia.

- Visceral fat accumulation is associated with insulin resistance and dyslipidaemia. Other cardiovascular risk factors should be addressed in all patients.

\subsection{Hypersensitivity}

- Rash with NNRTIs is common (more severe and frequent with NVP) in the first 6 weeks of therapy. If the rash is accompanied by systemic features (e.g. fever, elevated ALT or hepatitis), mucosal involvement or blistering, the NNRTI should be discontinued immediately and rechallenge must not be performed. If the rash is mild and occurs without these features, the NNRTI can be continued and the rash can be treated symptomatically with antihistamines and, possibly, topical steroids. Systemic steroids should not be used.

- In patients who develop rashes during the low-dose NVP 'lead in' phase (200 mg daily), the dosage must not be increased to $200 \mathrm{mg}$ 12-hourly until the reaction has completely resolved. This 'treatthrough' approach is only acceptable if the patient can carefully be observed, otherwise NVP should be substituted.

- There is a possible cross-reaction between NVP and EFV, although most studies report no evidence of this. It is acceptable to substitute EFV for NVP in the event of hypersensitivity, unless the reaction was severe. There are hardly any data on substituting NVP for EFV in the event of hypersensitivity; therefore, this substitution is not recommended. ${ }^{38}$

- $\mathrm{ABC}$ hypersensitivity is primarily a systemic reaction occurring within the first 8 weeks of therapy in approximately 3\% of cases. Fatalities may occur on rechallenge. Therapy must be discontinued and never re-introduced. The manifestations of hypersensitivity include fever, rash, fatigue and abdominal or respiratory symptoms. If there is any doubt concerning the diagnosis (e.g. if the patient has a cough with fever), then the patient should be admitted for observation. Symptoms progress if hypersensitivity is present. The hypersensitivity reaction has been shown to occur on a genetic basis, being virtually confined to the HLA-B ${ }^{\star} 5701$ allele, which is very uncommon in Africans. If affordable and available, this allele should be excluded prior to using $\mathrm{ABC}$ in populations where the allele occurs.

\subsection{Nephrotoxicity}

Analysis for serum creatinine and urine proteinuria must be performed at baseline in all patients to detect sub-clinical renal disease, as there is an increased risk of renal failure in HIV infection due to a variety of causes. The dose of NRTIs needs to be adjusted in renal failure (Table 9).

In a minority of patients, TDF may cause a tubular wasting syndrome (including wasting of phosphate and potassium). If patients receiving TDF develop muscle weakness or other muscle symptoms, then potassium and phosphate levels must be assessed. TDF can also cause acute renal failure, but this is uncommon. TDF should be discontinued immediately in patients with acute renal failure; it can be recommenced when the renal failure has resolved only if an alternative cause of renal failure is established.
It is essential to estimate the creatinine clearance before commencing TDF, which should not be used if the clearance is $<50 \mathrm{ml} / \mathrm{min}$. For patients receiving TDF, creatinine should be monitored at 3 months, 6 months and then 6-monthly. In high-risk patients (particularly those with co-existent hypertension or diabetes), creatinine should also be checked at 1 and 2 months. Long-term use of TDF with other nephrotoxic agents (e.g. aminoglycosides or NSAIDs) should be avoided. In patients in whom TDF is avoided because creatinine clearance is $<50 \mathrm{ml} / \mathrm{min}$ at baseline, it may be possible to switch to TDF at a later point if renal function improves. This is often the case if patients had chronic diarrhoea or other opportunistic infections at the time of ART initiation.

\subsection{Neuropsychiatric toxicity}

AZT and RAL frequently cause headaches when started, but this usually resolves. EFV frequently causes neuropsychiatric effects in the first few weeks of therapy, typically presenting with insomnia, vivid dreams and dizziness. Both dysphoria and euphoria may occur. Fortunately, these features subside in the majority of patients within the first $4-6$ weeks. Psychosis may occasionally occur. If the neuropsychiatric effects of EFV are not tolerated, then the patient should be switched to NVP or another alternative.

\subsection{Dysglycaemia}

The older PIs, notably IDV, may cause diabetes. However, the newer PIs (ATV, DRV and LPV) do not. Visceral fat gain, which occurs to a similar extent with all ARV classes, is associated with insulin resistance. Blood glucose should be assessed serially in these patients as part of a cardiovascular risk assessment.

\subsection{Gynaecomastia}

Gynaecomastia involves the development of breast tissue in men. This is not related to lipodystrophy. It may be bilateral or unilateral. Serum testosterone should be measured and replacement therapy given if this is low. Gynaecomastia is most consistently associated with EFV, so patients should be switched to NVP or another alternative.

\section{Immune reconstitution inflammatory syndrome (IRIS)}

Approximately $10-20 \%$ of patients who start ART with advanced immunosuppression experience clinical deterioration during the first months due to IRIS. Two forms are recognised: unmasking IRIS occurs in patients who have an unrecognised opportunistic infection when ART is started and who then present with an exaggerated inflammatory features of that infection during early ART due to it being 'unmasked' by recovering immunity; paradoxical IRIS occurs in patients who are being treated for an opportunistic infection when they start ART, but who develop an immune-mediated worsening or recurrence of features of that infection after starting ART. IRIS is most frequently described in association with TB and CM. Skin conditions such as molluscum contagiosum and Kaposi's sarcoma may also worsen due to IRIS. The diagnosis of IRIS can be difficult, mainly because there is no confirmatory diagnostic test. Diagnosis relies on recognition of the characteristic clinical presentation, ensuring that opportunistic infection(s) are correctly diagnosed, and excluding alternative causes for deterioration such as drug resistance (e.g. MDR-TB). Case definitions for TB and cryptococcal IRIS have been published. ${ }^{39,40}$ It is important to ensure that the underlying opportunistic 
infection is treated appropriately. ART should be continued, unless IRIS is life-threatening (e.g. neurological involvement in TB-IRIS with depressed level of consciousness). Corticosteroids have been shown to reduce morbidity and improve symptoms in paradoxical TB-IRIS, ${ }^{41}$ and can be used in mycobacterial and fungal forms of IRIS when other causes for deterioration have been excluded, and particularly when IRIS features are severe. ${ }^{42}$ Practical guidelines for TB-IRIS management have recently been published. ${ }^{43}$

\section{Third-line ART}

Third-line ART (also referred to as 'salvage' therapy) is used when a patient has experienced virological failure on drugs from the NRTI, NNRTI and PI classes (with documented PI resistance). Before considering third-line therapy, adherence interventions should be intensified and, if there is still no viral suppression, a resistance test must be performed to confirm the presence of resistance to the PI being used in second-line therapy. This test is very expensive and the patient must be on the failing ART at the time, as 'wild-type' HIV is more fit and outgrows the resistant mutant population which therefore cannot be detected within some weeks/months after cessation of ART. However, third-line regimens are also extremely expensive and are not justified if the patient does not have resistance necessitating such a switch. Data show that currently most patients failing second-line regimens in SA are infected with an HIV virus without PI mutations. In these patients, improved adherence is required rather than third-line regimens. The decisions regarding treatment choices in third-line therapy are complex and need to be guided by resistance patterns found on resistance testing. It is essential that resistance tests are interpreted in conjunction with a full ART history by an expert.

Current international guidelines promote the idea that virological suppression is a realistic goal for third-line therapy. This is certainly true with the availability of several new classes of ARV agents (entry inhibitors and InSTIs) together with newer PIs (DRV and tipranavir) and NNRTIs (ETV). ${ }^{44}$ As these drugs become available in the region for patients who require them, they provide the possibility of effective suppression with third-line therapy. DRV, ETV and the InSTI RAL are now registered in South Africa. No firm recommendations for a generic third-line regimen can be made and regimen choice should be individualised. An expert treater should always be consulted. A few guidelines regarding third-line ART regimens are further discussed:

- There is a need for specific adherence counselling in patients preparing to start third-line ART, with a frank discussion that this regimen is likely to be their last option for the foreseeable future.

- First-generation NNRTIs (NVP and EFV) have no place in third-line therapy as they do not impair viral fitness.

- A boosted PI with the broadest resistance profile should be selected (this is currently DRV). ${ }^{45}$ DRV must be used twice daily in this context (600 mg 12-hourly with $100 \mathrm{mg}$ ritonavir 12-hourly). LPV may be used if the drug is still active based on a resistance test (e.g. if the patient failed second-line ATV therapy).

- The addition of 3TC (or FTC) is recommended as the M184V mutation that it selects for impairs viral replication. Other NRTIs (the most active based on resistance testing) should also be added.

- Consideration of the addition of other salvage drugs (e.g. RAL ${ }^{46}$ and/or $\mathrm{ETV}^{47,48}$ ) will depend on genotype resistance test result and cost issues. RAL is preferred because it belongs to an entirely new class with no risk of cross-resistance from prior ART exposure in first- and secondline therapy. Because most patients are not receiving an NNRTI at the time of failing second-line therapy when a genotype resistance test is typically performed, prior NNRTI mutations related to first-line NNRTI failure may be archived at this time. Therefore, it is difficult to be certain from this genotype as to whether ETV is compromised; however, data from South Africa suggest that the majority of patients who have failed NVP or EFV are still susceptible to ETV. ${ }^{49}$

- We advise against double ritonavir-boosted PIs. ${ }^{1}$

- If viral suppression is not achieved on salvage therapy, there is still benefit in continuing failing ART because of the residual partial activity and 'crippling' effect of such ART. 'Crippling' describes the fact that mutant viruses often have less replicative capacity. Provided that the viral load can be maintained below 10000 copies $/ \mathrm{ml}$, the CD4 count will usually be maintained or even increase. ${ }^{30}$

For further guidance, the Southern African HIV Clinicians Society will be publishing ART resistance guidelines in late 2012.

\section{Support and counselling 17.1 ART-related counselling}

Many patients are afraid of starting ART. The patient should be reassured that the drugs work and that side-effects are usually minor and transient, or manageable. The patient should be given a treatment plan, specifying the reasons for commencing therapy and the drugs to be used (with names and details including the appearance of each drug, when and how they are to be taken, and a brief indication of anticipated side-effects and toxicity).

Adherence in the order of $95-100 \%$ is required for virological suppression. Poor adherence results in the development of drug resistance. The desire to stop therapy or alter the number or timing of the drugs must be avoided. The patient must be encouraged to discuss drug-related issues with his/her clinician before any changes are made.

\subsection{Lifestyle, nutrition, traditional medication and supplements}

A healthy lifestyle is recommended, including a balanced diet, plenty of exercise, giving up smoking, moderating alcohol and having a positive outlook on the future. Various adjuncts to therapy are widely used in the community. These include specific diets, food/nutritional supplements, vitamins and so-called immune 'boosters'. Scientific evidence to support the use of these is largely absent. Some herbs and high doses of trace elements and fat-soluble vitamins may cause harm and ought to be discouraged. There are also potentially important drug interactions between some herbal remedies and ARVs. For further guidance:

Southern African HIV Clinicians Society. Nutrition and HIV/AIDS: Nutritional guidelines for HIV-infected adults and children in Southern Africa: Meeting the needs. Southern African Journal of HIV Medicine 2007;8:22-32.

Southern African HIV Clinicians Society. Nutrition and HIV/AIDS: Nutritional guidelines for HIV-infected adults and children in Southern Africa: Meeting the needs. Southern African Journal of HIV Medicine 2008;9:34-59.

\subsection{Immunisations}

HIV infection is associated with a suppression of both humoral and cell-mediated immune response, which may impair the response to vaccinations reducing their efficacy, especially if the CD4 count is $<200$ cells $/ \mu$ l. The safety of live attenuated vaccination is also modified by HIV-infection and live vaccines are contra-indicated in symptomatic HIV disease or if the CD4 count is $<200$ cells/ $\mu$. The decision to use a vaccine must be based on best assessment of risks and benefits. 
Travellers to areas endemic for malaria and yellow fever need to be cautioned. The forested regions where contact with the mosquito vector and the virus is possible must be avoided. Yellow fever vaccination poses a risk to HIV-positive travellers whose $\mathrm{CD} 4$ count is $<200 \mathrm{cells} / \mu \mathrm{l}$. Such persons should be encouraged to make alternative arrangements or to travel with documentation that permits travel without prior vaccination.

\subsection{Opportunistic infections}

The use of appropriate prophylaxis (primary or secondary) is essential in patients initiating ART. In general, prophylaxis can be discontinued once the CD4 count has increased to 200 cells/ $\mu$ l (but certain minimal durations of prophylaxis apply for secondary prophylaxis - local and international guidelines should be consulted).

Funding and support. This work is supported and funded by the Southern African HIV Clinicians Society through an educational grant from Atlantic Philanthropies.

Conflict of interest. All expert panel members have completed and submitted conflict of interest disclosure forms. Disclosure information represents the previous 3 years (updated 17 August 2012) and includes relationships with pharmaceutical companies and medical aids: $\mathrm{Dr}$ Francesca Conradie has received support from Abbott to attend conferences, and research support from Tibotec. She has also received honoraria for speaking engagements from Abbott and MSD. Dr Hefer has received support to attend conferences from Abbott, Adcock Ingram, Aspen and MSD. He owns shares in Lifecell and has received honoraria for speaking engagements from Abbott, Aspen and MSD. Dr Johnson has received research support from Bristol Myers Squibb (BMS), MSD, Tibotec and Schering-Plough. He has also received honoraria for speaking engagements from Abbott. Professor Graeme Meintjes has received honoraria for speaking engagements from Sanofi Aventis and serves as a consultant for Aid for AIDS. Professor Yunus Moosa has received support to attend conferences from Abbott and honoraria for speaking at conferences/seminars from Abbott, Aspen, MSD and Pfizer. Dr Theresa Rossouw serves as a consultant for Discovery Health. Dr Ebrahim Variava receives support for clinical trials from Outsuka. Professor Francois Venter has received support to attend conferences from Adcock Ingram and MSD; honoraria for speaking engagements from MSD; and has served as a consultant for Abbott, Johnson and Johnson and Tibotec. Dr Eric Goemaere, Professor Gary Maartens, Dr Moeketsi Mathe, Dr Regina Osih and Dr Gilles Van Custem report no conflicts of interest.

\section{References}

1. Petersen ML, Wang Y, van der Laan MJ, Rhee SY, Shafer RW, Fessel WJ. Virologic efficacy of boosted double versus boosted single protease inhibitor therapy. AIDS 2007;21(12):1547-1554. [http://dx.doi.org/10.1097/QAD.0b013e32825a69a8]

2. Severe P, Juste MA, Ambroise A, et al. Early versus standard antiretroviral therapy for HIV-infected adults in Haiti. N Engl J Med 2010;363(3):257-265. [http://dx.doi. org/10.1056/NEJMoa0910370]

3. The CASCADE Collaboration. Timing of HAART initiation and clinical outcomes in human immunodeficiency virus type 1 seroconverters. Arch Intern Med 2011;171(17):1560-1569. [http://dx.doi.org/doi:10.1001/archinternmed.2011.401]

4. Cain LE, Logan R, Robins JM, et al. When to initiate combined antiretroviral therapy to reduce mortality and AIDS-defining illness in HIV-infected persons in developed countries: an observational study. Ann Intern Med 2011;154(8):509-515. [http://dx.doi.org/10.1059/0003-4819-154-8-201104190-00001]

5. Kitahata MM, Gange SJ, Abraham AG, et al. Effect of early versus deferred antiretroviral therapy for HIV on survival. N Engl J Med 2009;360(18):1815-1826. [http://dx.doi.org/10.1056/NEJMoa0807252]

6. Sterne JA, May M, Costagliola D, et al. Timing of initiation of antiretroviral therapy in AIDS-free HIV-1-infected patients: a collaborative analysis of $18 \mathrm{HIV}$ cohort studies. Lancet 2009;373(9672):1352-1363. [http://dx.doi.org/10.1016/S01406736(09)60612-7]

7. Cohen MS, Chen YQ, McCauley M, et al. Prevention of HIV-1 infection with early antiretroviral therapy. N Engl J Med 2011;365(6):493-505. [http://dx.doi. org/10.1056/NEJMoa1105243]

8. Badri M, Ehrlich R, Wood R, Pulerwitz T, Maartens G. Association between tuberculosis and HIV disease progression in a high tuberculosis prevalence area. Int J Tuberc Lung Dis 2001;5(3):225-232.

9. Abdool Karim SS, Naidoo K, Grobler A, et al. Integration of antiretroviral therapy with tuberculosis treatment. N Engl J Med 2011;365(16):1492-1501. [http://dx.doi. org/10.1056/NEJMoa1014181]

10. Blanc FX, Sok T, Laureillard D, et al. Earlier versus later start of antiretroviral therapy in HIV-infected adults with tuberculosis. N Engl J Med 2011;365(16):14711481. [http://dx.doi.org/10.1056/NEJMoa1013911]

11. Havlir DV, Kendall MA, Ive P, et al. Timing of antiretroviral therapy for HIV-1 infection and tuberculosis. N Engl J Med 2011;365(16):1482-1491. [http://dx.doi. org/10.1056/NEJMoa1013607]

12. Torok ME, Yen NT, Chau TT, et al. Timing of initiation of antiretroviral therapy in human immunodeficiency virus (HIV)--associated tuberculous meningitis. Clin Infect Dis 2011;52(11):1374-1383. [http://dx.doi.org/10.1093/cid/cir230]

13. Makadzange AT, Ndhlovu CE, Takarinda K, et al. Early versus delayed initiation of antiretroviral therapy for concurrent HIV infection and cryptococcal meningitis in sub-saharan Africa. Clin Infect Dis 2010;50(11):1532-1538. [http://dx.doi. org/10.1086/652652]

14. Zolopa A, Andersen J, Powderly W, et al. Early antiretroviral therapy reduces AIDS progression/death in individuals with acute opportunistic infections: A multicenter randomized strategy trial. PLoS One 2009;4(5):e5575. [http://dx.doi.org/10.1371/ journal.pone.0005575]

15. Riddler SA, Haubrich R, DiRienzo AG, et al. Class-sparing regimens for initial treatment of HIV-1 infection. N Engl J Med 2008;358(20):2095-2106. [http:// dx.doi.org/10.1056/NEJMoa074609]

16. Sax PE, Tierney C, Collier AC, et al. Abacavir-lamivudine versus tenofoviremtricitabine for initial HIV-1 therapy. N Engl J Med 2009;361(23):2230-2240. [http://dx.doi.org/10.1056/NEJMoa0906768]

17. Post FA, Moyle GJ, Stellbrink HJ, et al. Randomized comparison of renal effects, efficacy, and safety with once-daily abacavir/lamivudine versus tenofovir/ emtricitabine, administered with efavirenz, in antiretroviral-naive, HIV-1-infected adults: 48-week results from the ASSERT study. J Acquir Immune Defic Syndr 2010;55(1):49-57. [http://dx.doi.org/10.1097/QAI.0b013e3181dd911e]

18. Tan DH, Chan K, Raboud J, et al. Comparison of abacavir/lamivudine and tenofovir/emtricitabine among treatment-naive HIV-infected patients initiating therapy. J Acquir Immune Defic Syndr 2011;58(1):38-46. [http://dx.doi org/10.1097/QAI.0b013e3182282cfc]

19. Ribaudo HJ, Benson CA, Zheng Y, et al. No risk of myocardial infarction associated with initial antiretroviral treatment containing abacavir: short and long-term results from ACTG A5001/ALLRT. Clin Infect Dis 2011;52(7):929-940. [http:// dx.doi.org/10.1093/cid/ciq244]

20. Sabin CA, Worm SW, Weber R, et al. Use of nucleoside reverse transcriptase inhibitors and risk of myocardial infarction in HIV-infected patients enrolled in the D:A:D study: a multi-cohort collaboration. Lancet 2008;371(9622):1417-1426. [http://dx.doi.org/10.1016/S0140-6736(08)60423-7]

21. Cruciani M, Zanichelli V, Serpelloni G, et al. Abacavir use and cardiovascular disease events: a meta-analysis of published and unpublished data. AIDS 2011;25(16):1993-2004. [http://dx.doi.org/10.1097/QAD.0b013e328349c6ee]

22. Rawizza HE, Chaplin B, Meloni ST, et al. Immunologic criteria are poor predictors of virologic outcome: implications for HIV treatment monitoring in resourcelimited settings. Clin Infect Dis 2011;53(12):1283-1290. [http://dx.doi.org/10.1093/ $\mathrm{cid} / \mathrm{cir} 729$ ]

23. Manasa J, Katzenstein D, Cassol S, Newell ML, de Oliveira T. Primary drug resistance in South Africa: data from 10 years of surveys. AIDS Res Hum Retroviruses 2012;28(6):558-665. [http://dx.doi.org/10.1089/AID.2011.0284]

24. Smith CJ, Sabin CA, Lampe FC, et al. The potential for CD4 cell increases in HIV-positive individuals who control viraemia with highly active antiretroviral therapy. AIDS 2003;17(7):963-969. [http://dx.doi.org/10.1097/01. aids.0000060352.78202.79]

25. Guihot A, Tubiana R, Breton G, et al. Immune and virological benefits of 10 years of permanent viral control with antiretroviral therapy. AIDS 2010;24(4):614-617.

26. Kaufmann GR, Furrer H, Ledergerber B, et al. Characteristics, determinants, and clinical relevance of CD4 T cell recovery to $<500$ cells/microL in HIV type 1 -infected individuals receiving potent antiretroviral therapy. Clin Infect Dis 2005;41(3):361-372. [http://dx.doi.org/10.1086/431484]

27. Mocroft A, Phillips AN, Gatell J, et al. Normalisation of CD4 counts in patients with HIV-1 infection and maximum virological suppression who are taking combination antiretroviral therapy: an observational cohort study. Lancet 2007;370(9585):407413. [http://dx.doi.org/10.1016/S0140-6736(07)60948-9]

28. Tuboi SH, Pacheco AG, Harrison LH, et al. Mortality associated with discordant responses to antiretroviral therapy in resource-constrained settings. J Acquir Immune Defic Syndr 2010; 53(1):70-77. [http://dx.doi.org/10.1097/ QAI.0b013e3181c22d19]

29. Loutfy MR, Genebat M, Moore D, et al. A CD4+ cell count $<200$ cells per cubic millimeter at 2 years after initiation of combination antiretroviral therapy is associated with increased mortality in HIV-infected individuals with viral suppression. J Acquir Immune Defic Syndr 2010;55(4):451-459. 
30. Ledergerber B, Lundgren JD, Walker AS, et al. Predictors of trend in CD4-positive T-cell count and mortality among HIV-1-infected individuals with virological failure to all three antiretroviral-drug classes. Lancet 2004;364(9428):51-62. [http:// dx.doi.org/10.1016/S0140-6736(04)16589-6]

31. Hamers R, Sigaloff K, Wallis C, et al. Patterns of HIV-1 Drug-Resistance after First-line ART Failure and Response to Second-line ART in a Multi-country Cohort: Sub-Saharan Africa. 19th Conference on Retroviruses and opportunistic Infections. Seattle, 5 - 8 March 2012.

32. Wainberg MA, Zaharatos GJ, Brenner BG. Development of antiretroviral drug resistance. N Engl J Med 2011;365(7):637-646. [http://dx.doi.org/10.1056/ NEJMra1004180]

33. Davies G, Cerri S, Richeldi L. Rifabutin for treating pulmonary tuberculosis Cochrane Database Syst Rev 2007;(4):CD005159.

34. Bradshaw D, Chopra M, Kerber K, et al. Every death counts: use of mortality audit data for decision making to save the lives of mothers, babies, and children in South Africa. Lancet 2008;371(9620):1294-1304. [http://dx.doi.org/10.1016/S01406736(08)60564-4]

35. Ford N, Calmy A, Mofenson L. Safety of efavirenz in the first trimester of pregnancy: an updated systematic review and meta-analysis. AIDS 2011;25(18):2301-2304. [http://dx.doi.org/10.1097/QAD.0b013e32834cdb71]

36. World Health Organization. Use of efavirenz during pregnancy: A public health perspective. Geneva: WHO, 2012. http://www.who.int/hiv/pub/treatment2/ efavirenz/en/index.html (1 July 2012).

37. Soriano V, Puoti M, Bonacini M, et al. Care of patients with chronic hepatitis B and HIV co-infection: recommendations from an HIV-HBV International Panel. AIDS 2005;19(3):221-240.

38. Mehta $\mathrm{U}$, Maartens $\mathrm{G}$. Is it safe to switch between efavirenz and nevirapine in the event of toxicity? Lancet Infect Dis 2007;7(11):733-738. [http://dx.doi.org/10.1016/ S1473-3099(07)70262-1]

39. Haddow LJ, Colebunders R, Meintjes G, et al. Cryptococcal immune reconstitution inflammatory syndrome in HIV-1-infected individuals: proposed clinical case definitions. Lancet Infect Dis 2010;10(11):791-802. [http://dx.doi.org/10.1016/ S1473-3099(10)70170-5]

40. Meintjes G, Lawn SD, Scano F, et al. Tuberculosis-associated immun reconstitution inflammatory syndrome: case definitions for use in resource-limited settings. Lancet Infect Dis 2008;8(8):516-523. [http://dx.doi.org/10.1016/S14733099(08)70184-1]

41. Meintjes G, Wilkinson RJ, Morroni C, et al. Randomized placebo-controlled trial of prednisone for paradoxical tuberculosis-associated immune reconstitution inflammatory syndrome. AIDS 2010;24(15):2381-2390. [http://dx.doi.org/10.1097/ QAD.0b013e32833dfc68

42. Meintjes G, Scriven J, Marais S. Management of the Immune Reconstitution Inflammatory Syndrome. Curr HIV/AIDS Rep 2012;9(3):238-250. [http://dx.doi org/10.1007/s11904-012-0129-5]

43. Meintjes G, Sonderup MW. A practical approach to the diagnosis and management of paradoxical tuberculosis immune reconstitution inflammatory syndrome. Continuing Medical Education 2011;29(10):410-417.

44. Yazdanpanah Y, Fagard C, Descamps D, et al. High rate of virologic suppression with raltegravir plus etravirine and darunavir/ritonavir among treatment-experienced patients infected with multidrug-resistant HIV: results of the ANRS 139 TRIO trial. Clin Infect Dis 2009;49(9):1441-1449. [http://dx.doi.org/10.1086/630210]

45. Arasteh K, Yeni P, Pozniak A, et al. Efficacy and safety of darunavir/ritonavir in treatment-experienced HIV type-1 patients in the POWER 1, 2 and 3 trials at week 96. Antivir Ther 2009;14(6):859-864. [http://dx.doi.org/10.3851/1301]

46. Steigbigel RT, Cooper DA, Teppler $\mathrm{H}$, et al. Long-term efficacy and safety of Raltegravir combined with optimized background therapy in treatmentexperienced patients with drug-resistant HIV infection: week 96 results of the BENCHMRK 1 and 2 Phase III trials. Clin Infect Dis 2010;50(4):605-612. [http:// dx.doi.org/10.1086/650002]

47. Madruga JV, Cahn P, Grinsztejn B, et al. Efficacy and safety of TMC125 (etravirine) in treatment-experienced HIV-1-infected patients in DUET-1: 24-week results from a randomised, double-blind, placebo-controlled trial. Lancet 2007;370(9581):2938. [http://dx.doi.org/10.1016/S0140-6736(07)61047-2]

48. Lazzarin A, Campbell T, Clotet B, et al. Efficacy and safety of TMC125 (etravirine) in treatment-experienced HIV-1-infected patients in DUET-2: 24-week results from a randomised, double-blind, placebo-controlled trial. Lancet 2007;370(9581):39-48. [http://dx.doi.org/10.1016/S0140-6736(07)61048-4]

49. Stevens WS, Wallis CL, Sanne I, Venter F. Will etravirine work in patients failing nonnucleoside reverse transcriptase inhibitor-based treatment in southern Africa? J Acquir Immune Defic Syndr 2009;52(5):655-656. [http://dx.doi.org/10.1097/ QAI.0b013e3181balb00]

\section{Appendix: WHO stage 3 and 4 conditions (2006 revísion) WHO stage 3 conditions}

- unexplained severe weight loss (over $10 \%$ of presumed or measured body weight)

- unexplained chronic diarrhoea persisting for longer than 1 month

- unexplained persistent fever (intermittent or constant for longer than 1 month)

- persistent oral candidiasis

- oral hairy leukoplakia

- pulmonary TB (current)

- severe bacterial infections (e.g. pneumonia, empyema, pyomyositis, bone or joint infection, meningitis, bacteraemia, severe pelvic inflammatory disease)

- acute necrotising ulcerative stomatitis, gingivitis or periodontitis

- unexplained anaemia $(<8 \mathrm{~g} / \mathrm{dl})$, neutropaenia $\left(<0.5 \times 10^{9} / \mathrm{l}\right)$ and/or chronic thrombocytopenia $\left(<50 \times 10^{9} / 1\right)$.

\section{WHO stage 4 conditions}

- HIV wasting syndrome

- pneumocystis pneumonia

- recurrent severe bacterial pneumonia

- chronic herpes simplex infection (orolabial, genital or anorectal of more than 1 month's duration or visceral at any site)

- oesophageal candidiasis (or candidiasis of trachea, bronchi or lungs)

- extrapulmonary TB

- Kaposi's sarcoma

- cytomegalovirus infection (retinitis or infection of other organs)

- central nervous system toxoplasmosis

- HIV encephalopathy

- extrapulmonary cryptococcosis including meningitis

- disseminated non-tuberculous mycobacteria infection

- progressive multifocal leukoencephalopathy

- chronic cryptosporidiosis

- chronic isosporiasis

- disseminated mycosis (extrapulmonary histoplasmosis, coccidiomycosis)

- recurrent septicaemia (including non-typhoidal salmonella)

- lymphoma (cerebral or B cell non-Hodgkin)

- invasive cervical carcinoma

- atypical disseminated leishmaniasis

- symptomatic HIV-associated nephropathy

- symptomatic HIV-associated cardiomyopathy. 


\section{Supplementary material 1. Starting ART in hospital}

Starting ART in eligible patients in an inpatient setting can be considered in certain circumstances, and should be strongly considered during prolonged hospitalisation, where adherence, toxicity management and other support can be directly provided. However, limited data have shown what many experienced clinicians predicted - that patients who are initiated on ART within the hospital have high default rates. This may be due to several factors - patients who wait to become severely ill and enter hospital may still have high levels of denial; they may be too ill to take in adherence counselling; and discharge may not be managed well. The clinician must carefully weigh up the high risk of deferring ART in terms of mortality and morbidity, and the risk for the individual patient of default which cannot easily be predicted.

If a patient is considered for initiation in hospital, the following should be attended to:

\section{In hospital}

- Before discharge, the patient must understand the reasons for initiation of ART

- If the patient is too ill/not mentally competent, a caregiver and/or family member who will act as a directly observed therapy supporter should be involved

- Care should be exercised regarding ART drug interactions with concomitant medication.

\section{On discharge}

- Give very clear ART clinic directions, with a referral letter and details of documentation needed by the clinic

- Patients should be encouraged to attend the ART clinic as soon as possible for an appointment and should be informed of reasonable clinic appointment waiting times

- Sufficient medication must be provided to last to the ART clinic visit

- These patients are often discharged on newly initiated TB treatment; few programmes as yet offer integrated TB/ART clinical services, and the need for separate clinical visits should be carefully explained

- Discharging patients directly into the care of adequately counselled family members can be invaluable.

\section{High-risk patients}

Patients who are at high risk for early mortality, IRIS and ART sideeffects include:

- patients with a low BMI, anaemia and low albumin levels

- patients with newly diagnosed opportunistic illness, especially TB and $\mathrm{CM}$

- patients with low CD4 counts.

These patients should be initiated on ART as quickly as possible after any underlying opportunistic illnesses have been addressed (note the specific guidelines regarding ART timing in TB and CM in the guidelines), and should be counselled about the risk of IRIS, which may be misinterpreted as ART side-effects. Ideally, patients should have access to rapid referral systems, in the events of experiencing complicated IRIS or side-effects.

In addition, patients with any of the following are at high risk of default or inadequate adherence:

- uncontrolled depression
- poverty

- ambivalence about their HIV status

- distrust of the formal health sector

- lack of home support or high levels of community stigma

- alcohol or other substance abuse

- post-partum women.

Adherence issues are addressed in the Southern African Antiretroviral Resistance Treatment Guidelines, and include attention to treating mental illness and substance use, giving access to support groups, addressing potential workplace related issues including drug toxicity issues, additional counselling if denial is an issue, honest discussions about alternative health providers and churches that may undermine adherence, better post-partum integration of women/child HIV services, and actively linking poorer patients to poverty alleviation programmes.

\section{Common ART misconceptions}

- You cannot take ART if you do not have food available. None of the commonly used first- and second-line options have meaningful food restrictions. Patients should be warned that their appetite may return and that this may even be uncomfortable. However, food insecurity should be managed actively through rapid referral, and this should never be a reason to delay ART initiation.

- Doses need to be taken at precisely the same time each day. This myth was especially prevalent in the earlier days of ART, with anecdotes of patients returning to clinic in despair, after having interrupted their therapy for several weeks after missing a dose due to oversleeping by an hour. Encouraging patients to establish a routine helps with adherence, but delayed dosing is rarely a problem, even if out by many hours. Most of the drugs have long half-lives, and patients should be told simply to take their dose once they remember to do so. - You must never drink alcohol again. Heavy alcohol use may affect adherence, and may potentiate the hepatic toxicity of ART and other hepatic pathology. However, data do not support the commonly held notion that alcohol speeds up the progression to AIDS, nor is there any evidence that moderate alcohol use has any negative effect on the health of HIV-positive individuals. Local guidelines for the general population around responsible alcohol use should be followed; prohibition is not advocated.

- Disclosure is a prerequisite for ART. This myth probably followed early experiences with highly rationed ART, where all possible adherence strategies were aggressively pursued to optimise outcomes, and bringing in a 'treatment buddy' was required to access ART. However, it became a form of punishment by some unsophisticated counsellors and clinicians, often under the pretext of preventing transmission, through making HIV status public. This tactic is almost certainly illegal and certainly unethical, and while disclosure may assist patients with support and adherence, this should be suggested and based on the patient's individual circumstances. Forced disclosure can result in violence at the hands of a partner or community, and undermines confidence in confidentiality within the entire health system. Patients should be counselled about the pro's and cons of disclosure, and assisted through the process as needed.

- Unprotected sex causes virological failure. This myth probably emerges from a convoluted understanding of the transmission of resistant virus. Theoretically, unprotected sex with someone who is failing ART may allow for the passage of resistant virus, but this is unusual. 
Patients should be counselled about safe sex, however, unprotected sex itself will not result in virological failure.

\section{Adherence interventions}

Causes of poor adherence are often complex and linked to social issues. Common causes include:

- Inadequate treatment literacy. Most HIV programmes have extraordinary adherence rates when compared with other chronic diseases; this is largely due to effort being made to ensure patients understand HIV. If a patient fails therapy, some examination of the pre-ART counselling may be merited.

- Side-effects. Side-effects are a very common reason for patients to default therapy. A careful history of often subtle but distressing side-effects (bad dreams, sleepiness, poor concentration, nausea, loss of appetite, change of body shape), in conjunction with a work history (shift work in particular) may allow for drug substitutions. Subtle lipo-atrophy changes from D4T and AZT are often not taken seriously by healthcare providers, until disfiguring. Regular enquiry and immediate drug substitutions where possible should form part of every healthcare worker encounter.

- Depression and other mental illnesses. Undiagnosed or undertreated depression and other mental illness (the frequency of major depression is 2 times higher in HIV-positive subjects than in matched HIV-negative subjects) may undermine adherence. Patients with depression usually respond well to an anti-depressant medication in combination with non-pharmaceutical interventions. If they do respond it should be given for at least 6 months.

- Poverty and food insecurity. Both of these have been related to poor adherence and increased missed clinic visits. Patients often lose their jobs due to ill health during the period leading up to ART initiation, and should be encouraged to return to the job market as soon as feasible or to seek support. This may lead to moving away from the ART clinic, and referral must be facilitated. Access to available grants, social support and employment non-governmental organisations (NGOs) may provide additional support.

- Work-related issues. These include shift work and ability to attend clinic visits on weekdays. They are a major cause of poor adherence. Long clinic waiting times, including monthly pick-ups, may make holding down a job untenable, especially with an unsympathetic employer. Clinicians should try to encourage clinics to be flexible, run smoothly for healthy patients, and provide 3 - 6-monthly pharmacy refills.

- Substance use. Excessive alcohol use may cause significant problems with adherence. In addition, other recreational drugs may cause problems in certain parts of the country, and use fluctuates according to availability and fad.

- Social problems. Stigma and poor social support networks. Perceived stigma is correlated with poor adherence; this may manifest in a fear of tablets being found, an inability to solicit family or partner support, or anxiety regarding an employer, neighbours or a community. Social support groups may assist.
- Denial. Initiation of ambivalent, conflicted patients on ART is unlikely to have a successful outcome. Involvement of family members and partners may be an effective mechanism for addressing denial.

- Pill burden. This is less of an issue than previously, but must be considered in patients who are failing treatment. Dosing simplification should be a major part of advocacy within public sector programmes.

- Altered fertility intentions. HIV-discordant or -concordant couples may spontaneously decide to cease their ART regimen as they intend to begin a family; sympathetic and facilitatory fertility counselling during ART initiation counselling, should prevent this.

- Conflict of opinions. Conflict of opinions on the use of ARVs occurs frequently between healthcare providers, certain alternative health providers and churches. This is best addressed with an honest and non-judgmental conversation

\section{Practical adherence tools}

Tools such as pillboxes, diaries and setting alarms may help patients to remember to take their medication. Having an emergency supply of a single dose on hand (e.g. in the handbag or workbag) may be useful for situations when patients have unexpected delays in getting home. Medicine formulations and trade names may change, and patients should be educated to recognise the generic name of their current regimen to avoid confusion. 